\title{
Late Holocene Aboriginal Shellfish Production Strategies in Northern Australia: Insights from Prunung (Red Beach), Weipa, Cape York Peninsula
}

\author{
Michael Morrison \\ Department of Archaeology, Flinders University, GPO Box 2100, Adelaide SA 5001, Australia \\ mick.morrison@flinders.edu.au
}

\begin{abstract}
Recent investigations into the role of shell mounds in late Holocene Aboriginal economies in northern Australia have focussed on one of the key constituents in mound sites: the intertidal bivalve, Tegillarca granosa (formerly Anadara granosa). Various researchers have suggested that shell mounds were constructed during production activities that were predominantly oriented towards exploitation of estuarine or marine ecosystems, with other resources being of secondary or supplementary importance during these times. Proponents of this model concede that it requires ongoing evaluation in relation to new quantitative data on mound composition, stratigraphy and chronology from shell mound sites across a range of different environmental contexts. At Weipa, in western Cape York Peninsula, recent research has been oriented toward collecting new data necessary for investigating the role of mound sites and the production strategies associated with their formation. In this paper, the results of excavations and analysis of a series of shell mounds at Prunung (Red Beach), to the north of Weipa, are presented. These results support the view that mound construction took place in the context of production activities strategically oriented towards intertidal flats, rather than broadly-based foraging within local site catchments, or a more generalised 'estuarine' orientation.
\end{abstract}

\section{Introduction}

A considerable focus of north Australian shell mound research relates to understanding the dynamics of Aboriginal food production strategies in coastal environments and how these strategies articulated with local ecosystems throughout the mid-to-late Holocene. While a range of models have been proposed, a common view is that shell mound formation can be directly tied to foraging activities focussed upon the species Tegillarca granosa, a marine bivalve commonly found in mound sites (Bourke 2005; Clune and Harrison 2009; Morrison 2003, 2013a; Veitch 1999). For instance, at Point Blane Peninsula, in northeast Arnhem Land (Figure 1), Faulkner (2013) has suggested that ecological changes contributing to the proliferation of $T$. granosa in local environments enabled higher intensity exploitation and an associated shift towards semi-sedentary occupation of locations adjacent to highly productive shell fishing locales. At Albatross Bay, on the other side of the Gulf of Carpentaria (Figure 1), it has been similarly suggested that mound formation was heavily tied to this species (Morrison 2003), but that the scale and intensity of shellfish production was highly variable, shifting in relation to local ecosystem dynamics at multiple time scales (Morrison 2013a).

One issue that has important implications for these models, however, is the increasing number of investigations that illustrate that while $T$. granosa is often very abundant, it can no longer be seen to be the primary emphasis of food production linked to shell mound formation. For instance, on Vanderlin Island, Sim and Wallis (2008:101) report one shell mound where the most common shellfish species were the bivalve Marcia hiantina together with $T$. granosa. Similarly, Rosendahl, Ulm et al. (2014a) report the occurrence of numerous marine gastropod shell mounds (Terebralia spp. and Telescopium telescopium) on Mornington Island, in the southern Gulf of Carpentaria, indicating a foraging emphasis on mangrove communities, while other mounds evidence large proportions of Anadara antiquata and
Placuna placenta. At Weipa, surface observations strongly point to a predominant emphasis on T. granosa (Bailey 1994; Morrison 2013a), however, recent work points to subtle internal variations in shellfish composition, with instances where $M$. hiantina comprises between $27 \%$ and $39 \%$ of shellfish MNI, while Saccostrea cucullata comprises between $55 \%$ and $30 \%$ of total shellfish MNI (Morrison 2013b:181). Several other studies have also shown that mound surfaces sometimes include a limited range of other species - often bivalves collected from intertidal mud and sand flats (Cochrane 2014; Cribb 1986; Hiscock and Mowat 1993). Further afield, shell mounds on the southern Curtis Coast (Ulm 2006) and Booral (Frankland 1990) in central and southeast Queensland are dominated by Saccostrea glomerata, with lower proportions of other taxa, including Anadara trapezia. Such results highlight the need for ongoing detailed fieldbased assessments of shell mound chronology, composition and stratigraphy from a diverse range of chronological and environmental settings throughout northern Australia. This will enable the development of more robust models of the dynamic ways in which Aboriginal people have drawn on specific kinds of ecosystems and resources through time, and through that, enable the further evaluation of resource production models.

This paper contributes to this endeavour by reporting on the results of excavation and analysis of shell mound sites at Prunung (Red Beach) (Figure 1), a few kilometres north of Weipa in western Cape York Peninsula. The Prunung study area is a sandy beach ridge plain on the lower reaches of the Mission River. A small complex of shell mound sites occur on the foredune while several more isolated sites occur away from the central mound group (Figure 2). Some of these sites have been subject to previous work (Bailey et al. 1994) and some sense of the age structure of the beach ridge exists through earlier geomorphological research (Stone 1995). Excavations at Prunung took place within a regional programme of 


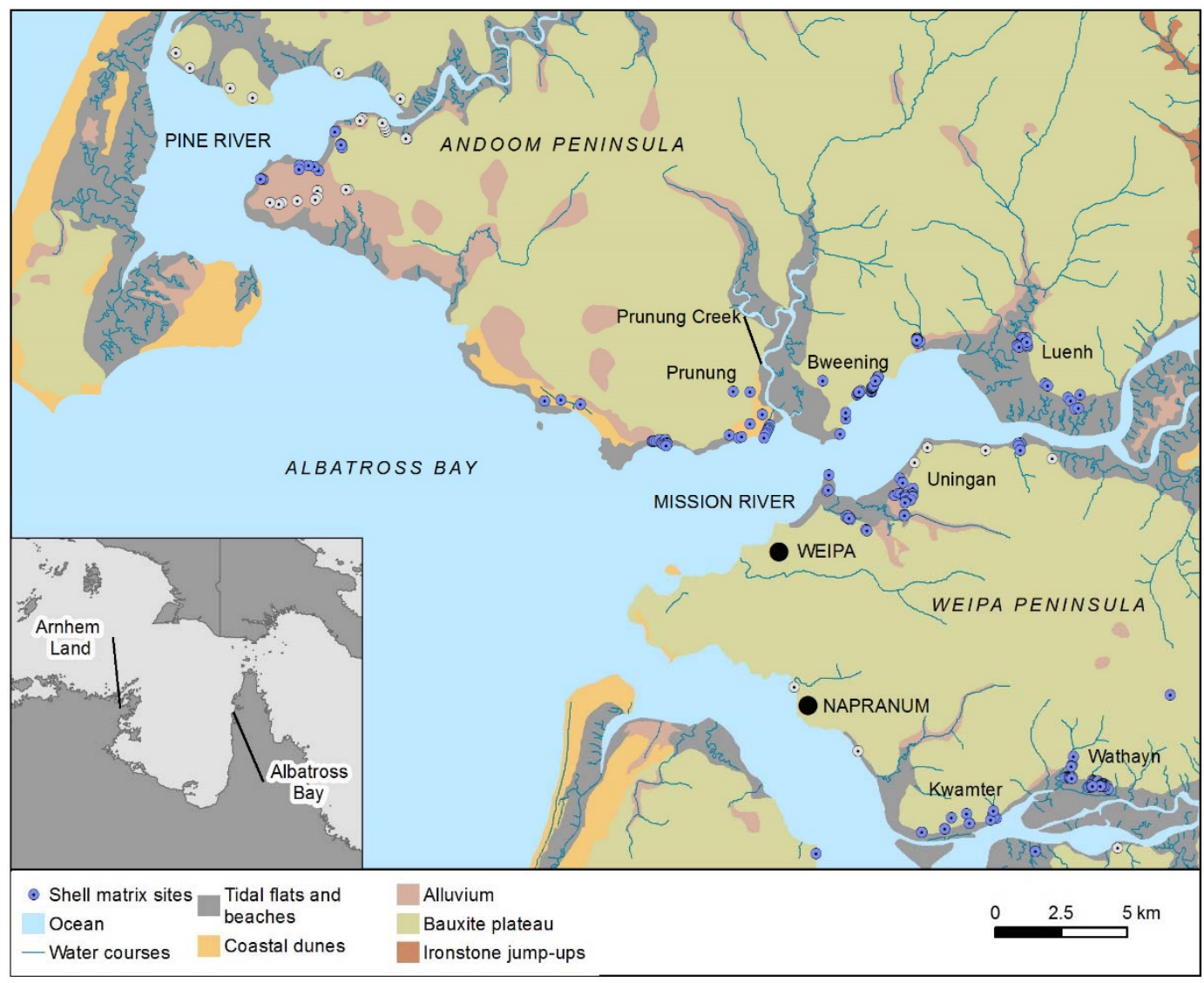

Figure 1. The Mission River showing location of known shell matrix sites and places mentioned in text.

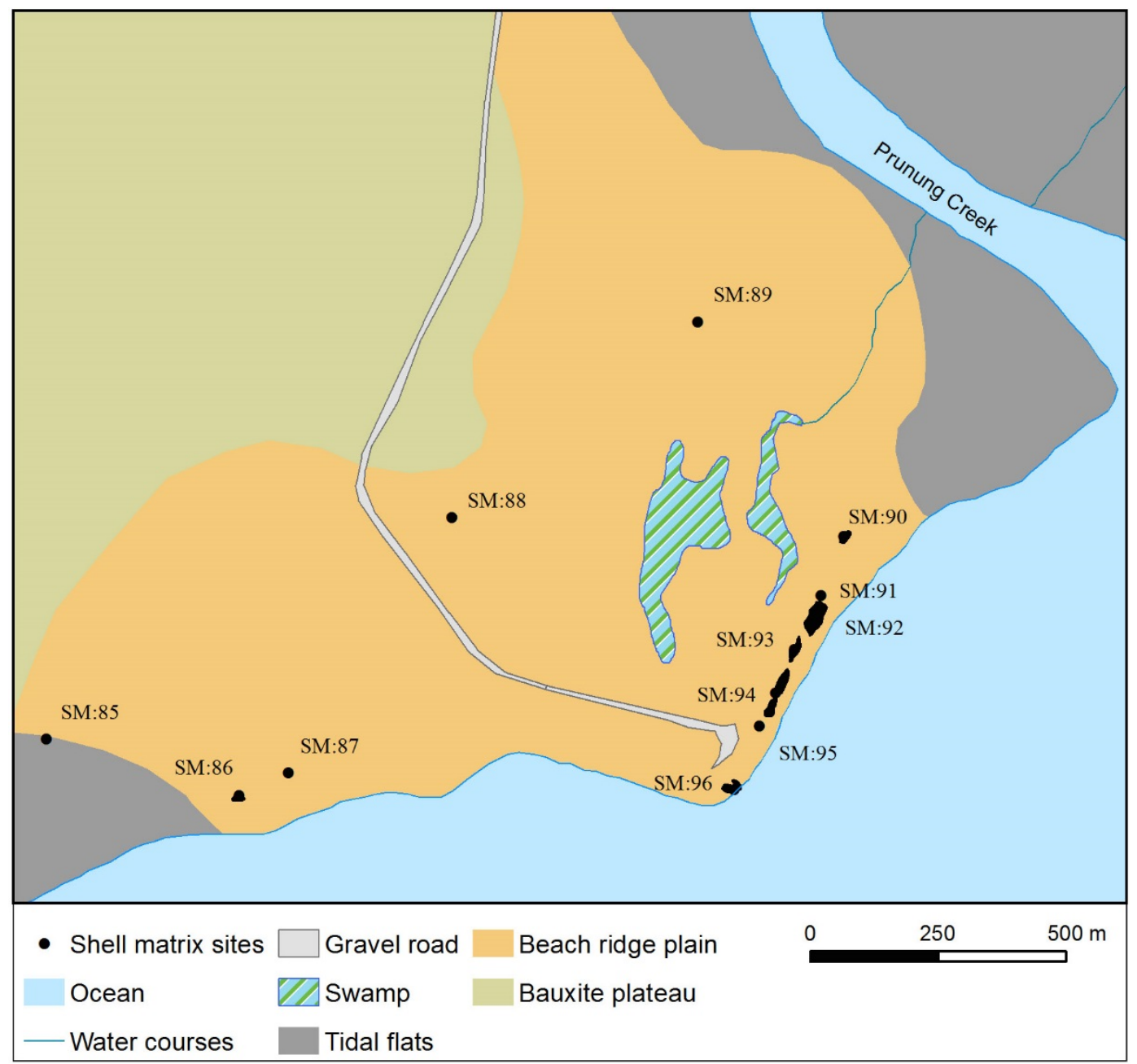

Figure 2. The Prunung study area. 
archaeological investigations oriented towards understanding the role of shell mounds in late Holocene Aboriginal societies in the region (Morrison 2010, 2013a, $2013 \mathrm{~b}, 2014)$ and set out to address three specific aims. Firstly, at the time excavations were conducted (2003), previous excavations at Weipa (Bailey 1977, 1994, 1999; Bailey et al. 1994; Wright 1971) had generated limited comparative data on mound composition. As such, the excavations aimed to obtain more detailed comparative data, particularly on mound composition and chronology, to complement similarly oriented research within the adjacent Bweening area (Morrison 2013b). Secondly, most previously excavated sites occur within or near open woodland and either on bauxite-dominant regolith or prograded coastal plains, abutted by mangrove forests and extensive intertidal mudflats. The Prunung sites occur in a very different environmental context - a beach ridge plain within open dune woodland, adjacent to a large semipermanent freshwater swamp. As such, the second aim of the Prunung excavations were to investigate whether mound composition varied in relation to environmental context within the Albatross Bay catchment. The final aim of this work was to evaluate specific claims by Stone (1995) that mounds at Prunung are wave and wind-sorted chenier deposits and were neither constructed or used by Aboriginal people.

\section{The Study Area}

Prunung is a clan estate within the Thanakwith language area on the lower reaches of the Mission River (Fletcher 2007). The coastal portion of this clan estate is a beach ridge plain that is characterised by a series of low but distinct shore-parallel ridges that have formed adjacent to the Weipa bauxite plateau (Figure 2). These ridges run approximately southeast to northwest and are most distinct in the northwest near Prunung (Andoom) Creek, but converge into one body towards the point (Stone 1995). Surface observations indicate that sediments in these ridges vary from fine dark sand with high proportions of organic material and gravel (mostly bauxite pisoliths) inland, to cleaner yellow and white sands nearer to contemporary shorelines, with greater proportions of whole shell and shell hash. A diverse range of common estuarine and marine shellfish species can be observed in these natural shell deposits, particularly those associated with mud and sand flat environments.

The beach ridge plain is vegetated by dune woodland that is relatively open near the coast and increases in density further to the west. A seasonal swamp occurs on the beach ridge plain and vegetation here varies between Melaleuca spp. forest in seasonally inundated areas, to occasional stands of dry notophyll vine forest in more elevated localities. Much of the southwest facing shoreline is undergoing significant erosion which has exposed a long, near-continuous section of the beach ridge substrates and the seaward portion of a single large shell mound. The beach ridge deposit contains distinct T. granosa-dominated strata and fine shell hash within a matrix of fine sand.

Between the early 1950s and mid-1970s, Prunung was used as a landing point for small barges transporting mine equipment from Weipa to areas further north and since the late 1970s has been a popular recreation area, particularly for fishing. Both activities have caused distinct impacts including clearing, vegetation removal and vehicle traffic, all of which seem to have contributed to the destruction and disturbance of some shell matrix sites. Large amounts of gravel have also been used to create a vehicle track into the area across the sandy substrates (Figure 2).

\section{Geomorphology}

Relatively little geomorphological research has been conducted within the Albatross Bay region although some of the most substantial studies to date have focussed on the formation of beach ridge plains on the Mission River. Hayne (1992) conducted an investigation of a beach ridge at Bowchati, near Prunung (Figure 1) and suggested that accumulation of sandy sediments began here after $\sim 2,500$ BP. He argued that the formation of the beach ridge plain was triggered by changes in longshore sediment transport along the Gulf of Carpentaria that led to an increase in deposition of sandy sediments within exposed areas of Albatross Bay at this time. Importantly though, Hayne's work focussed principally on the coastal margin of the plain. Field surveys conducted by the author indicate that this plain extends well inland of the areas sampled by Hayne, and transitions to fine yellow and orange coloured sands that point to an earlier phase of deposition and possibly a relict early Holocene dune system similar to those identified in the southwestern Cape York Peninsula (Rhodes et al. 1980).

Stone (1995) undertook a more comprehensive analysis of the formation of the Prunung beach ridge sequence, analysing and dating auger samples taken along three transects. This work revealed a complex depositional environment, with the transect nearest Prunung Point being composed of upper sediments of sand mixed with bauxite pisoliths underlain by shelly sands containing pisoliths and shell fragments, which were interpreted as a former sandy intertidal flat (Stone 1995:85). Towards Andoom Creek the seaward ridges contain larger proportions of T. granosa but this diminishes in the more inland ridges. The beach ridge deposits themselves overlay silts and clays. Eight conventional radiocarbon determinations were used as a basis for constructing a chronology for the development of the beach ridges. These indicated that the most seaward ridge on which the shell mound deposits occur was less than 800 years old (Stone 1995:92), while the two most landward ridges were between $2790 \pm 80 \mathrm{BP}$ (ANU-8036) and $4530 \pm 80$ BP (ANU-8038).

Stone noted a series of mound features overlaying these deposits. These included three shell mound features composed mainly of T. granosa near the point, and two other mounds that he viewed as being similar despite being composed largely of sand with very low proportions of $T$. granosa and other marine shell. Stone's auguring programme included only two samples on distinct shell mounds, and these were retrieved from cross-section A-B (Stone 1995:87, Figure 6(a)). Neither of these samples targeted the primary mound deposit, and instead appear to have been taken from the landward and seaward margins of the shell mound respectively. This is a major limitation in this sampling programme, since it is highly likely that intermixing of anthropogenic shell and underlying natural sediments occurred at the mound's margin, particularly on the seaward mound face where storm surges are evident today. Despite limited sampling of shell mound deposits, Stone interpreted them as having been naturally formed as a result of the processes that contributed to beach ridge 

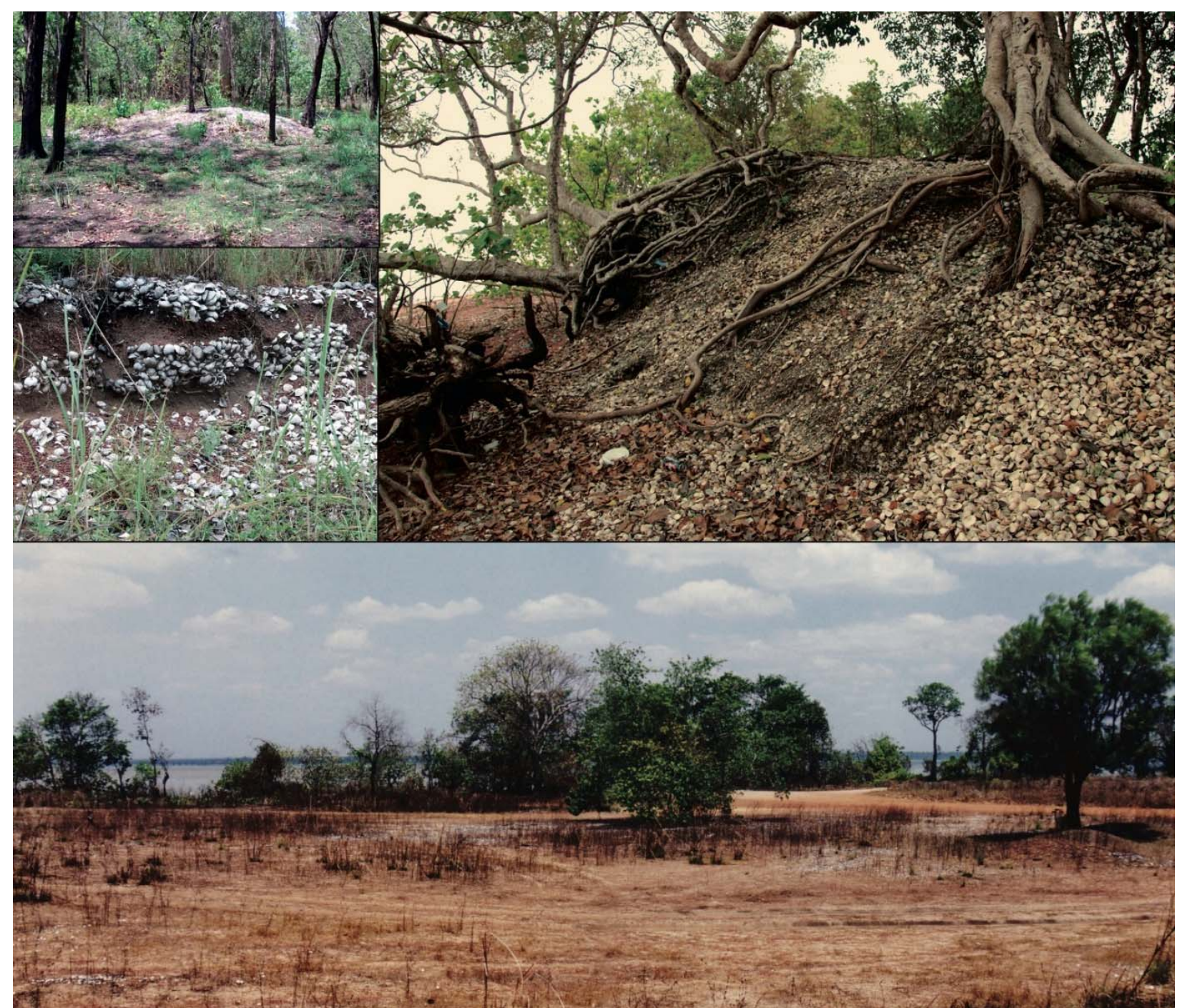

Figure 3. Natural and cultural shell deposits at Prunung. Top right, SM:96; top left, SM:88; centre left, exposed beach ridge deposits along southwest-facing shoreline; bottom, foredune area showing major shell mound deposits.

formation and differential winnowing at the point. $\mathrm{He}$ suggested that the mounds occur only at the point because "the terrigenous sediment normally mixed with them diminishes with increasing distance from its source at the mouth of Andoom Creek" and that here in this exposed location, "more effective wave-action also results in better sorting" (Stone 1995:93-94). Stone concluded that these deposits were coarse shell berms formed through geomorphological processes, and "there is no evidence to suggest that any of this shell was collected by Aborigines for food" (Stone 1995:94).

\section{Archaeology}

The history of land-use and disturbance at Prunung introduces some difficulties in terms of identifying anthropogenic shell deposits, particularly at the point where site disturbance has been extensive. A number of surface deposits of shell that occur on the beach ridge plain may be redeposited mound material, while the low elevation of the beach ridge and the proximity of the area to the high water mark means that natural deposits of shell are also likely, as is frequently the case with such substrates (Sullivan and O'Connor 1993). For this reason, in this project, field surveys focussed on identifying distinct mound deposits rather than scatters. A similar perspective was adopted by Bailey et al. (1994).

The most substantial shell mound deposits occur to the north east of Prunung Point, where a series of elongated $T$. granosa dominated shell mounds up to $2 \mathrm{~m}$ in height occur parallel to the present shoreline (Figure 2). These sites are all partially covered by small thickets of vine forest (Figure 3). Sites SM:90-94 are largely undisturbed by recent activities such as earthmoving or quarrying, however, the area around SM:95 and SM:96 appears to have been subject to ground disturbance, with substantial amounts of likely anthropogenic deposits removed or spread out onto the surrounding substrates. SM:96 has also been the focus of unreported sampling, as a trench approximately $1.5 \mathrm{~m}$ wide and $5 \mathrm{~m}$ long has been excavated across its western margins. This occurred prior to work at the site in 1993 by Bailey et al. (1994), who also noted its occurrence. Furthermore, quarrying has occurred at the landward face of the mound, removing an estimated $30-50 \%$ of the mound deposit. SM:95 has also been heavily modified by ground disturbance, and field assessments undertaken as part of this research found that the surface and margins of this mound were highly irregular with clear evidence of quarrying and the redeposition of mound sediments. 
Almost 1,000m due west of Prunung Point is SM:86, a $0.5 \mathrm{~m}$ high $T$. granosa mound located on a slight natural promontory adjacent to a natural gap in the mangrove forest (Figure 3). A second shell mound, SM:88, was located $\sim 750 \mathrm{~m}$ northwest of SM:96, at the very rear of the beach ridge plain and on a low distinct ridge that has formed alongside the margin of the bauxite laterite plateau (Figure 3). This site measured $0.75 \mathrm{~m}$ in height and its surface composition was predominantly $T$. granosa and had been subject to minor quarrying activity in the past. Significantly, sandy substrates around SM:96 have very low amounts of natural shell and contain far more bauxite pisoliths - presumably derived from the immediately adjacent plateau - than those closer to the contemporary shoreline.

\section{Methods}

The author carried out excavations at Prunung during a 10 day field trip in October 2003 with a supplementary six day field trip during October 2004. Analysis of excavated materials took place during 2004 and 2005. The methods used for this work are essentially the same as those reported for earlier research conducted at Bweening (Morrison 2013b:167). This involved controlled excavation of test pits $(0.5-1 \mathrm{~m} 2$ in size) using small hand tools, with deposits removed in $3-5 \mathrm{~cm}$ arbitrary spits. All materials excavated were weighed and sieved through $6 \mathrm{~mm}$ and $2 \mathrm{~mm}$ nested sieves.

Thanakwith custodians stipulated that efforts be taken to minimise the removal of cultural materials from the site, partly to ensure that the sites could be immediately backfilled and rehabilitated. These efforts were successful as today there is no surface indication of where the excavations took place, an important requirement of Thanakwith Traditional Owners (Richard Barkley, pers. comm., 2003; Stephen Hall, pers. comm., 2003; Grace John, pers. comm., 2003). Excavation revealed that the bulk of mound deposits were T. granosa valves and so one of two sampling strategies was used to remove these materials. These strategies have been outlined in detail elsewhere and as such are not discussed again here (see Morrison 2013b:167). In several cases, small 25-30 $\mathrm{cm}^{2}$ test pits were excavated by hand on the flanks of mound sites to obtain preliminary radiocarbon determinations.

Samples for radiocarbon dating were collected in situ from exposed sections. T. granosa has been the primary sample material used, with each sample consisting of either very large, intact valves where these were available, or alternatively, 2-3 valves selected because of their close spatial arrangement whilst in situ. All samples were submitted to the University of Waikato Radiocarbon Dating Laboratory and subject to standard pretreatment procedures for marine shell. All conventional radiocarbon ages (CRAs) were calibrated with CALIB version 6.10 (Stuiver et al. 2005) using the SHCAL13 and MARINE13 calibration datasets (Hogg et al. 2013; Reimer et al. 2013). Marine reservoir correction factors have an important influence on interpretation of calibrated determinations on marine shellfish (Ulm 2002) and this is of special importance where finer chronological trends and patterns are under consideration, as is the case here. Petchey et al. (2013) suggest an Anadara spp. (including T. granosa in their study) correction factor of $-71 \pm 15$ radiocarbon years for the southeastern coast of Papua New Guinea though here the more regionally specific Gulf of Carpentaria local $\Delta \mathrm{R}$ value of $-103 \pm 16$ radiocarbon years (Ulm et al. in prep.) is used as per other recent research in the region (Morrison 2013b, 2014; Rosendahl, Ulm et al. 2014a; Shiner et al. 2013). All calibrated radiocarbon ages are presented here at the $2 \sigma(95 \%$ confidence $)$ level and individual ages are given as calibrated age ranges. Where relevant, median values for $2 \sigma$ calibrated age ranges, rather than the intercept, are used as the basis of statistical summaries of radiocarbon data (after Telford et al. 2004).

\section{Results \\ SM:96}

SM:96 is the most prominent shell mound at Prunung and is also the most heavily disturbed (Figure 3). A large proportion of the mound - perhaps half of the original deposit - has been quarried on the landward face while the exposed seaward section is heavily eroded. No new investigations were conducted on SM:96 as part of this project and so the results of previous excavations are presented here in order to provide a clearer picture of broader trends and patterns within the study area. Beaton (1984) had previously obtained several radiocarbon determinations for samples obtained from this mound as part of an unpublished research project though these lack any contextual data (Stone 1995). Bailey et al. (1994) obtained further determinations on samples retrieved from the mound along with compositional data from column samples on anthropogenic and natural deposits both at SM:96 and on a sand-dominated mound near Andoom Creek, which they interpret as a megapode mound.

Investigations of SM:96 were focussed on the eroded seaward face of the mound in order to investigate relationships between the shell mound deposit and adjacent substrates (Bailey et al. 1994:75) (Figure 4). The stratigraphy is described as comprising layers of relatively clean T. granosa alternated with layers of shell-rich, dark earthy matrix (Bailey et al. 1994:76). The former layers were interpreted as representing periods of rapid shell deposition and the latter as reflecting periods of slow accumulation. Column sample RB1-11 cut through the SM:96 deposit and into the underlying substrates. Composition and particle size analysis of these samples revealed that shell mound deposit was dominated by $T$. granosa with low proportions of materials often associated with natural deposits including pisoliths, fine shell hash or other materials under $1 \mathrm{~mm}$ in size. The most marked change in the column is at RB10 and RB11, which are interpreted by Bailey et al. (1994) as being natural sandy substrates upon which the shell matrix deposit has accumulated (Figure 5). The RB West column has low proportions of T. granosa and moderate to high proportions of sediment $<1 \mathrm{~mm}$ in diameter (Figure 6). Proportions of fine shell hash are similar or lower than those of the RB19 column samples and the numbers of pisoliths are similar or greater. The differences between both deposits were statistically highly significant (Bailey et al. 1994:76-77) and support the view that SM:96 was sufficiently distinct from surrounding substrates to be an anthropogenic deposit. Similar investigations of a sand-dominated mound adjacent to Prunung Creek also showed statistically strong differences compared with the shell mound deposit, but high similarities with the beach deposits. They interpreted this latter site as a megapode mound. 


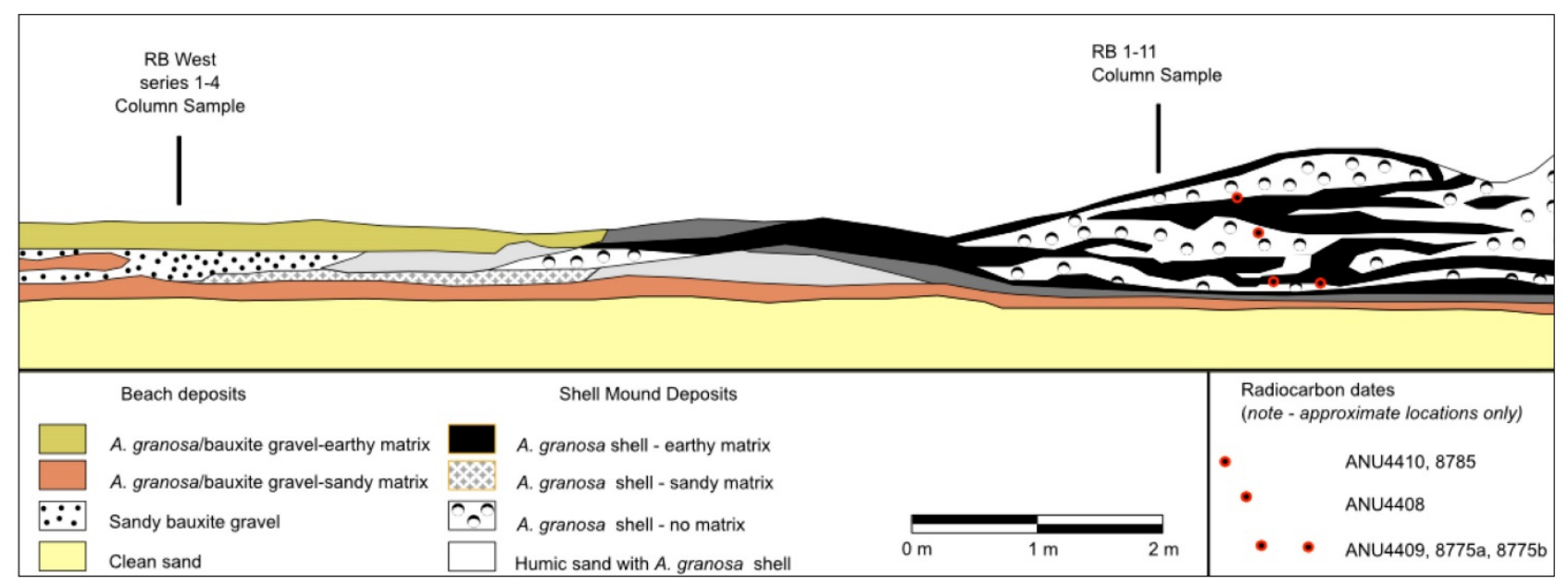

Figure 4. SM:96 section showing relationships between mound and beach ridge deposits (after Bailey et al. 1994).

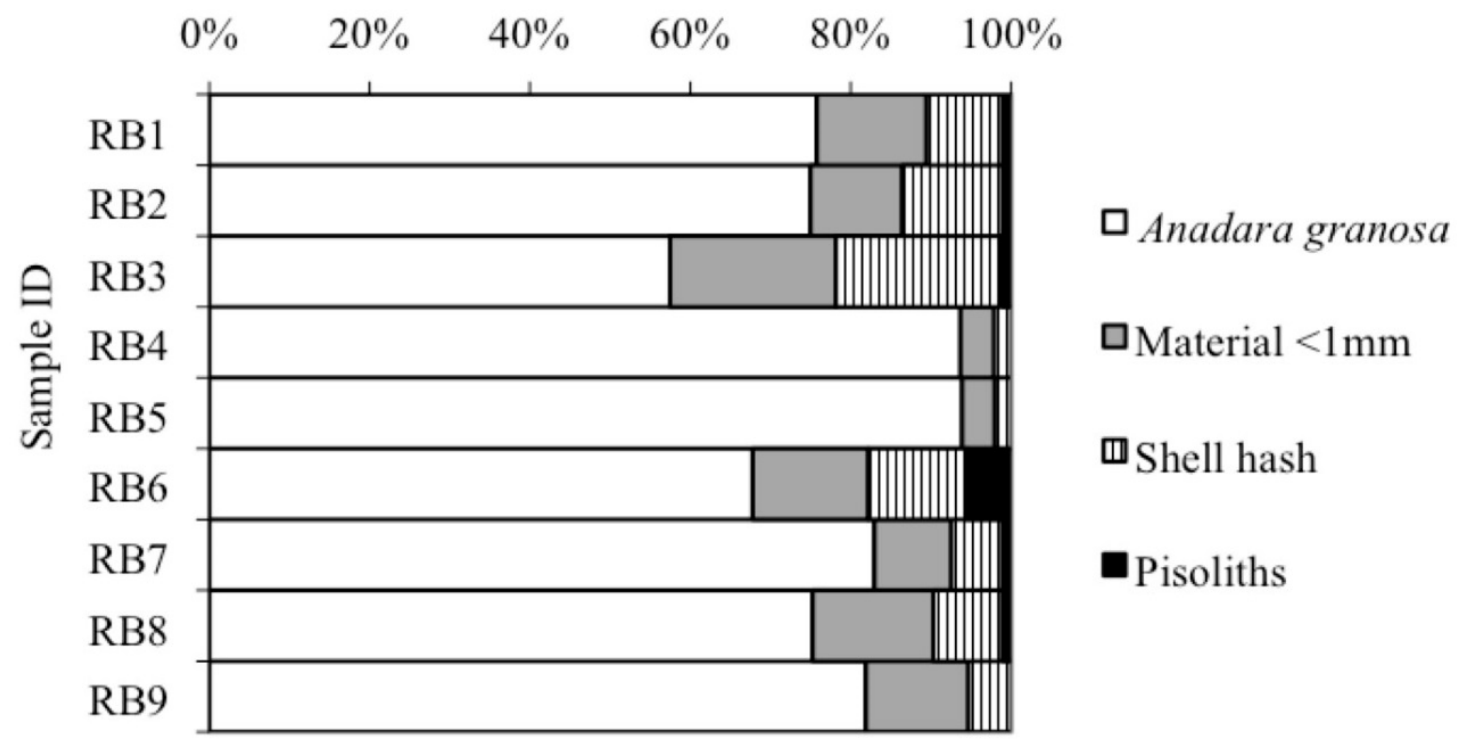

Figure 5. RB1-9 column sample composition, SM:96 (after Bailey et al. 1994:Table 2).

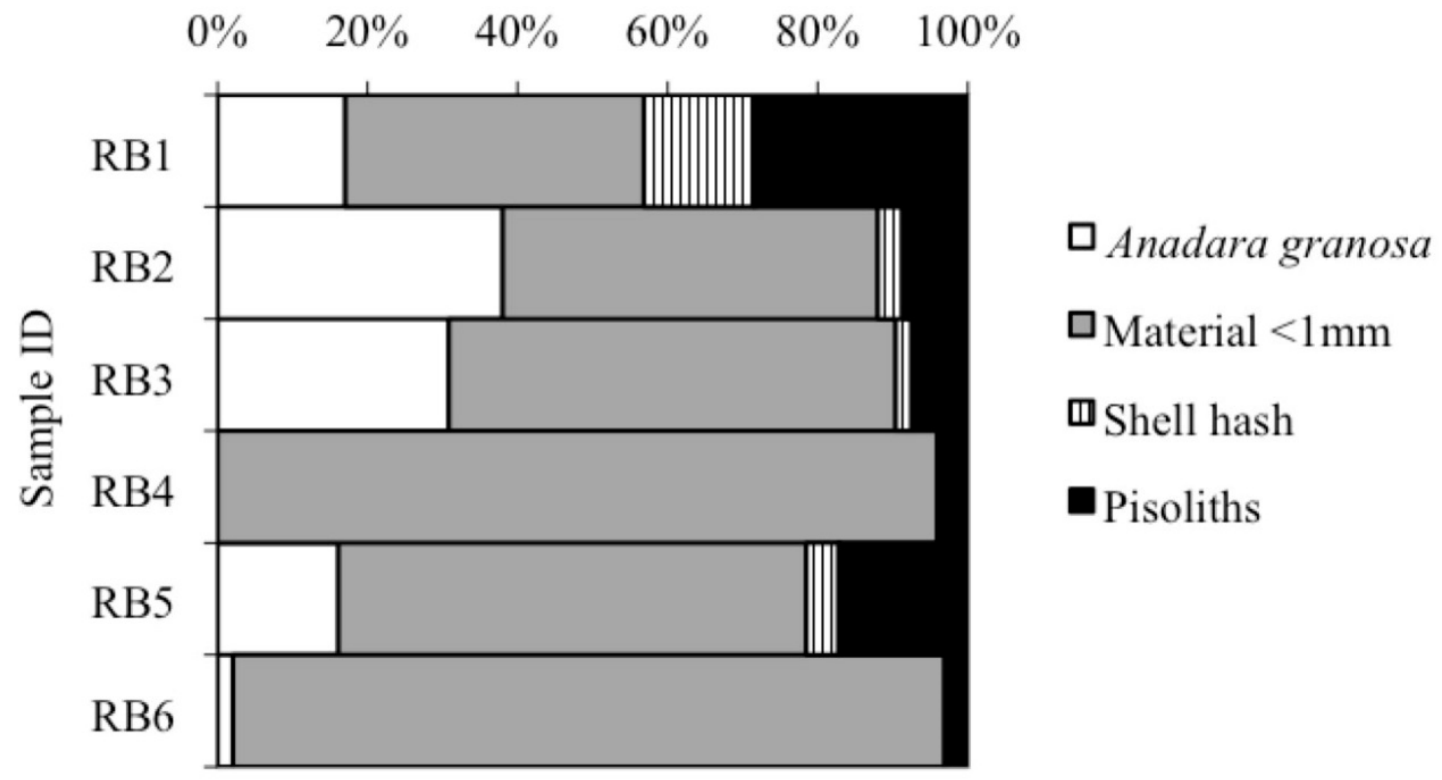

Figure 6. RB West column sample composition (after Bailey et al. 1994:Table 2). 
Table 1. Radiocarbon determinations and calibration data for Prunung.

\begin{tabular}{|c|c|c|c|c|c|c|c|}
\hline Site & Lab. No. & $\begin{array}{c}{ }^{14} \text { C Age } \\
\text { (years BP) }\end{array}$ & $\begin{array}{l}\delta^{13} \mathrm{C} \\
(\%)\end{array}$ & 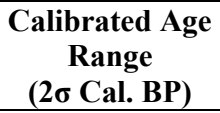 & Position & Sample & Depth \\
\hline SM:86 & Wk-13787 & $738 \pm 40$ & -1.7 & $381-539$ & Lower & T. granosa & $30 \mathrm{~cm}$ \\
\hline SM:88 & Wk-14508 & $633 \pm 38$ & -1.6 & $289-463$ & Upper & T. granosa & $21 \mathrm{~cm}$ \\
\hline SM:88 & Wk-14509 & $780 \pm 35$ & -1.5 & $431-560$ & Lower & T. granosa & $65 \mathrm{~cm}$ \\
\hline SM:90 & Wk-14506 & $980 \pm 32$ & -1.8 & 559-708 & Lower & T. granosa & $40 \mathrm{~cm}$ \\
\hline SM:91 & Wk-13788 & $469 \pm 43$ & -1.7 & $1-4$ & Upper & T. granosa & $25 \mathrm{~cm}$ \\
\hline SM:92 & Wk-14507 & $898 \pm 37$ & -1.5 & $518-649$ & Lower & T. granosa & $75 \mathrm{~cm}$ \\
\hline SM:93 & Wk-11861 & $1096 \pm 42$ & -1.9 & $658-859$ & Lower & T. granosa & $97 \mathrm{~cm}$ \\
\hline SM:93 & Wk-11862 & $901 \pm 42$ & -2 & $515-654$ & & T. granosa & $63 \mathrm{~cm}$ \\
\hline SM:93 & Wk-11863 & $853 \pm 46$ & -1.6 & $487-636$ & Upper & T. granosa & $23 \mathrm{~cm}$ \\
\hline SM:96 & ANU-4408 & $790 \pm 60$ & -1.6 & $412-628$ & & T. granosa & Middle \\
\hline SM:96 & ANU-4409 & $760 \pm 75$ & -2 & $324-616$ & Lower & T. granosa & Basal \\
\hline SM:96 & ANU-4410 & $360 \pm 100$ & -1.5 & $1-276$ & Upper & T. granosa & Surface \\
\hline SM:96 & ANU-8775a & $790 \pm 110$ & 0 & $297-664$ & Lower & T. granosa & Base \\
\hline SM:96 & ANU-8775b & $1060 \pm 130$ & 0 & $1220-1257$ & Lower & Charcoal & Base \\
\hline SM:96 & ANU-8785 & $890 \pm 70$ & 0 & $479-681$ & Upper & T. granosa & Surface \\
\hline
\end{tabular}

A range of radiocarbon determinations are available for SM:96 (Table 1). Beaton initially obtained three determinations from the site (see Stone 1995); those from the base and middle returned calibrated ages of 324-616 cal BP (ANU-4409) and 412-628 cal BP (ANU-4408) while a third surface sample was 1-276 cal BP (ANU4410). Bailey et al. (1994) obtained additional radiocarbon samples from the mound. Two of these were basal dates: one obtained on a charcoal sample returned an age of 1220-1257 cal BP (ANU-8775b) and a second on $T$. granosa was 297-664 cal BP (ANU-8775a). A nearsurface sample returned an age of 479-681 cal BP (ANU8785).

A number of irregularities exist in the determinations on SM:96. The most significant of these is that calibrated determinations for the paired samples ANU-8775a and ANU-8775b do not overlap within $2 \sigma$ age-ranges. This can partly be explained as a disparity caused by the marine reservoir effect (Morrison 2014). Secondly, ANU-8775a is approximately $1 \mathrm{~m}$ lower in the section than ANU-8785, yet the calibrated determinations - both of which were from samples of T. granosa - are effectively contemporaneous, possibly indicating relatively rapid accumulation and the imprecision of a $2 \sigma$ age span. In addition, Beaton obtained near contemporaneous dates on T. granosa samples taken from the middle and basal layers of the section (ANU-4408 and ANU-4409). Taken together, these inconsistencies suggest that intermixing of older and younger deposits have occurred on this site during or subsequent to its formation. Today, SM:96 has the highest degree of exposure to storm surges and high winds from the west and this is likely to have been the case during its period of formation. As such, it is conceivable that older deposits have been redeposited on the upper mound surface, or that more recent deposits were reworked into older ones. Further, as described earlier, quarrying activity and storm surges have had a severe impact on the site (Figure 3 ) and this may have also led to intermixing or redeposition from other parts of the mound; for example, through movement of the deposit seaward as earth moving equipment worked on the landward face of the site.

Given these issues, chronological data from SM:96 are used cautiously here and the anomalous determination
(ANU-8775b) on charcoal is rejected. Basal determinations indicate that the site commenced forming by at least 297-664 cal BP with upper deposits accumulating relatively rapidly. This is consistent with Stone's (1995) suggestion that the underlying beach deposits were established only after 800 BP. Cessation of site accumulation appears to have occurred within the lower limit of the calibration curves.

\section{SM:93}

SM:93 is a low elongated shell mound $50 \mathrm{~m}$ long, up to $18 \mathrm{~m}$ in width, and is oriented roughly parallel with the adjacent shoreline (Figure 2). The site overlies the gradually sloping face of the most seaward beach ridge and is a maximum of $1.8 \mathrm{~m}$ high, with its peak occurring near the centre of the site. At the time of excavation, the surface of the site appeared to have only minor surface disturbances caused by shallow animal burrowing and fallen trees. Approximately $30 \%$ of the surface of the site was covered by a thicket of dry notophyll vine forest and up to $20 \mathrm{~cm}$ of humic material had accumulated in many areas. The remainder of the mound surface was exposed, clean whitegrey shell with little surface vegetation beyond occasional grasses or low shrubs.

A single $1 \mathrm{~m}^{2}$ test pit was excavated on a relatively level area on the upper surface of SM:93 to a depth of $120 \mathrm{~cm}$ below the site surface (Figure 7), revealing a deposit consisting primarily of densely-packed shell. Variations in the proportions or colour of soil, degree of shell fragmentation and the presence of ashy sediments were the basis for defining various strata within the section. These consisted of an upper surface layer of densely-packed and highly fragmented shell in a matrix of fine dark soil, with frequent rootlets and humic matter (Layer A). Underlying deposits consisted of loosely-packed shell that varied only in terms of the proportions of fine sediment including ash (Layers B, C, D, I, J L) with fine lenses of yellow sand (Layers E, G and K) and ash-rich fine sediment (Layers $\mathrm{F}$ and $\mathrm{H}$ ). The lower deposits of the site abruptly transitioned to yellow-brown then white sands with frequent bauxite pisoliths and negligible marine shell. No marine shell was observed in the basal layer (Layers $\mathrm{N}$ and $\mathrm{O}$ ). 


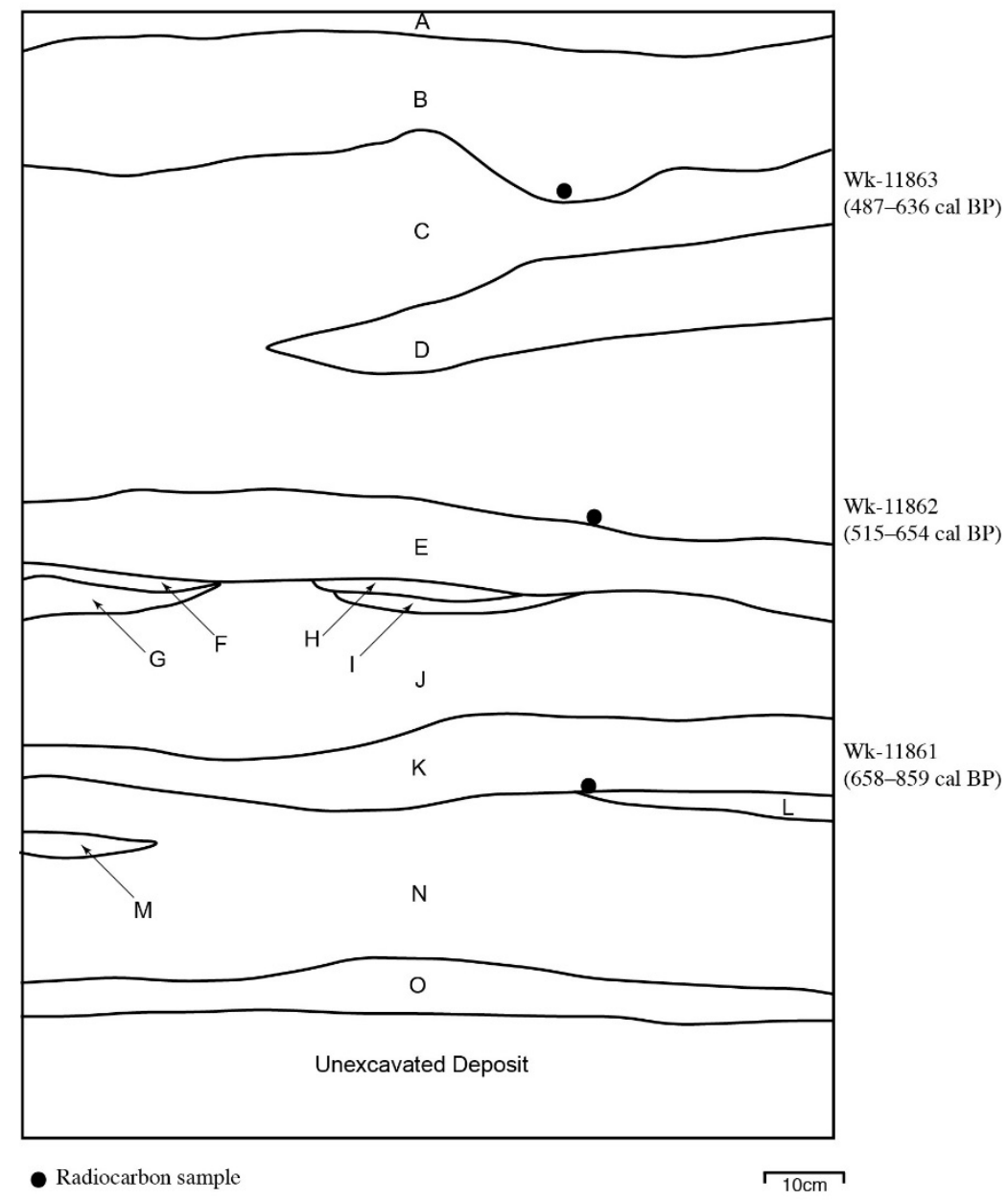

Figure 7. Section Profile, SM:93 (east).

Layer Descriptions: (A) Densely-packed shell, highly-fragmented with dark fine soil matrix and frequent fine roots. (B) Layer of loosely-packed and mostly whole shell dominated by T. granosa (Tg) with occasional M. hiantina (Mh). Negligible soil matrix, sparse roots. (C) Loosly-packed shell (Tg and Mh), mostly whole but with higher proportions of fine dark soil similar than in B. (D) Mostly fragmented shell with large proportions of dark soil matrix. (E) Intrusion of yellow sand containing frequent bauxite pisoliths. (F) Small intrusion of very ashy material containing large amounts of highly-fragmented shell and charcoal. (G) Intrusion of yellow sand containing frequent bauxite pisoliths. $(\mathrm{H})$ Small intrusion of very ashy material containing large amounts of highly-fragmented shell and charcoal. (I) Ashy sediment containing frequent fragmented shell and higher proportions of dark soil matrix than adjacent layers. (J) Shell dominated layer of mostly whole shell (Tg and Mh). Little sediment. (K) Intrusion of yellow sand containing frequent bauxite pisoliths. (L) Densly-packed brittle shell (Tg and S. cucullata). Small amounts of fine yellow sandy sediment throughout. (M) Yellow to brown sand with frequent bauxite pisoliths. Negligible marine shell. Culturally sterile deposit. (N) White to yellow fine sand with frequent bauxite pisoliths. No marine shell. Culturally sterile deposit. (O) As per N, but with fewer bauxite pisoliths.

Three samples of $T$. granosa were collected and submitted for radiocarbon determinations from SM:93. Calibrated ages suggest accumulation of the deposit commenced around 658-859 cal BP (Wk-11861). Wk11862 was obtained from the base of Layer C, approximately the middle of the section, and returned a determination of 515-654 cal BP. The third radiocarbon sample was obtained from the interface between the upper limit of Layer C and the lower portion of Layer B; the resulting determination was 487-636 cal BP (Wk-11863). The most recent deposits at the surface were not dated.

The most frequently occurring cultural material recovered in the $6 \mathrm{~mm}$ sieve residues was marine shellfish (Tables 2 and 3). The proportions of non-diagnostic shellfish are highest in the upper $15 \mathrm{~cm}$ of deposit and this correlates with the observation of more highly fragmented shell in the upper layers of the section profile. Excavation Units (XUs) 4 through 13 evidenced the highest proportions of diagnostic shellfish, and this correlates with the layers of densely-packed mostly whole shell that were observed in the stratigraphic section. The proportions of non-diagnostic shell steadily increase with depth below XU12.

Estimates of relative species abundance based on MNI calculations demonstrate that $T$. granosa is by far the most frequently occurring shellfish species throughout the deposit (Table 3 and Figure 8). T. granosa consistently represents over $70 \%$ of the total shellfish MNI in XUs 1 to 18. The lower XUs 19-23 have overall lower numbers of shellfish and T. granosa makes up a smaller proportion of the total MNI for each of these layers. No diagnostic shellfish occurred in the sand-dominated basal layers. Marcia hiantina is the second-most frequently occurring shellfish species based on MNI estimates, and peaks in the proportions of this species as a percentage of the total shellfish MNI occur in XUs 1 and 2 (17-18\%), 10-15 (20- 
Table 2. Summary data, SM:93.

\begin{tabular}{|c|c|c|c|c|c|c|c|}
\hline $\mathbf{X U}$ & $\begin{array}{c}\text { Mean Depth } \\
(\mathrm{cm})\end{array}$ & $\begin{array}{l}\text { Gross } \\
\text { (g) }\end{array}$ & $\begin{array}{c}\text { 6mm Shell } \\
(\mathrm{g})\end{array}$ & $\begin{array}{l}\text { Non-Diagnostic } \\
\text { Shell (g) } \\
\end{array}$ & $\begin{array}{c}\text { Diagnostic } \\
\text { Shell (g) }\end{array}$ & $\begin{array}{c}\text { Charcoal } \\
(\mathrm{g})\end{array}$ & $\begin{array}{c}\text { Other } \\
\text { Stones (g) }\end{array}$ \\
\hline 1 & 2.86 & 41900 & 26337.30 & 18009.50 & 8327.80 & - & 59 \\
\hline 2 & 8.07 & 48200 & 42111.10 & 25562.00 & 16549.10 & 0.6 & 56 \\
\hline 3 & 12.86 & 50700 & 48712.10 & 21042.50 & 27669.60 & 3.0 & 31 \\
\hline 4 & 18.15 & 35200 & 27510.60 & 2794.50 & 24716.10 & 2.0 & 5 \\
\hline 5 & 23.05 & 39700 & 34010.21 & 3529.50 & 30480.71 & 3.0 & 3 \\
\hline 6 & 27.73 & 42700 & 32893.01 & 5727.51 & 27165.50 & 14.7 & 9 \\
\hline 7 & 33.00 & 36400 & 29954.01 & 3796.90 & 26157.11 & 5.5 & 122 \\
\hline 8 & 36.25 & 12400 & 11732.71 & 1995.90 & 9736.81 & 3.0 & 13 \\
\hline 9 & 39.45 & 36000 & 31504.70 & 4673.00 & 26831.70 & 6.0 & 7 \\
\hline 10 & 44.86 & 37000 & 34880 & 6597.00 & 28283.00 & 2.5 & 22 \\
\hline 11 & 50.81 & 43000 & 41188.80 & 5245.00 & 35943.80 & 7.0 & 20 \\
\hline 12 & 56.40 & 46900 & 39258.50 & 5632.00 & 33626.50 & 12.5 & 18 \\
\hline 13 & 60.64 & 35700 & 21575.80 & 4940.00 & 16635.80 & 24.0 & 419 \\
\hline 14 & 65.55 & 50700 & 28283.40 & 9974.00 & 18309.40 & 28.0 & 40 \\
\hline 15 & 70.56 & 37200 & 16559.30 & 7260.00 & 9299.30 & 20.0 & 61 \\
\hline 16 & 75.31 & 46400 & 23858.10 & 8157.50 & 15700.60 & 32.0 & 12 \\
\hline 17 & 79.48 & 33000 & 18708.22 & 4255.02 & 14453.20 & 49.0 & 86 \\
\hline 18 & 84.54 & 46000 & 25489.50 & 8106.00 & 17383.50 & 37.0 & 13 \\
\hline 19 & 89.61 & 43600 & 17376 & 7462.00 & 9914.00 & 12.0 & 17 \\
\hline 20 & 93.80 & 50400 & 17544.60 & 6238.00 & 11306.60 & 35.0 & 117 \\
\hline 21 & 99.38 & 49200 & 4657.50 & 1193.00 & 3464.50 & 5.0 & 415 \\
\hline 22 & 104.61 & 41000 & 2199 & 1282.00 & 917.00 & 2.0 & 631 \\
\hline 23 & 109.09 & 41900 & 702.50 & 443.00 & 259.50 & 1.0 & 407 \\
\hline 24 & 116.06 & 87900 & - & - & - & - & - \\
\hline
\end{tabular}

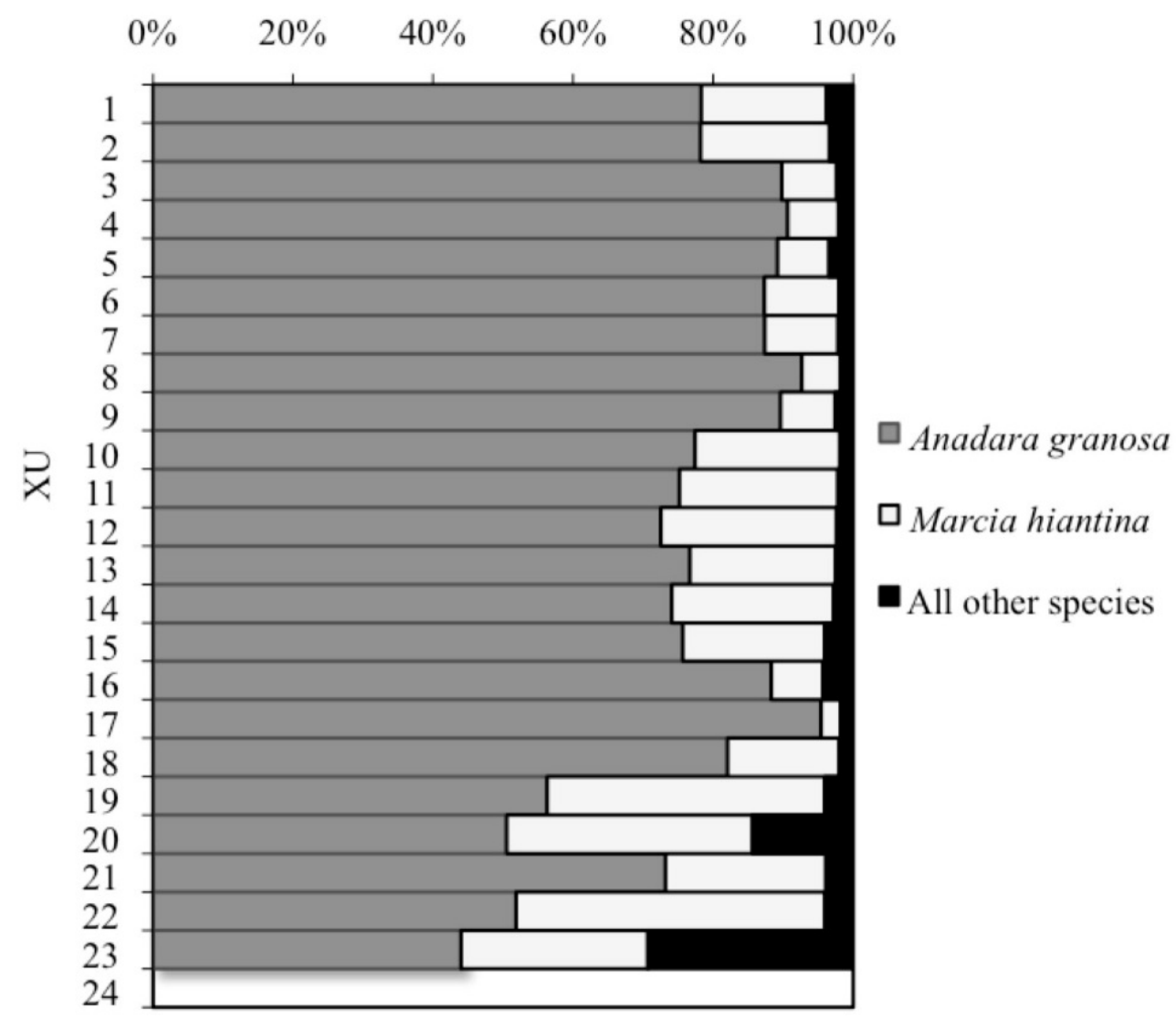

Figure 8. Shellfish MNI data, SM:93. 
Table 3. Shellfish quantification data, SM:93.

\begin{tabular}{|c|c|c|c|c|c|c|c|c|c|c|c|c|c|c|c|}
\hline \multirow[t]{2}{*}{$\mathbf{X U}$} & \multirow{2}{*}{$\begin{array}{l}\text { Mean } \\
\text { Depth } \\
\text { (cm) }\end{array}$} & \multicolumn{2}{|c|}{ XU Totals } & \multicolumn{4}{|c|}{ Tegillarca granosa } & \multicolumn{4}{|c|}{ Marcia hiantina } & \multicolumn{4}{|c|}{ All other species } \\
\hline & & MNI & $\begin{array}{c}\text { Weight } \\
\text { (g) }\end{array}$ & MNI & $\begin{array}{l}\text { MNI } \\
(\%)\end{array}$ & $\begin{array}{l}\text { Weight } \\
\text { (g) }\end{array}$ & $\begin{array}{c}\text { Weight } \\
(\%)\end{array}$ & MNI & $\begin{array}{l}\text { MNI } \\
(\%)\end{array}$ & $\begin{array}{c}\text { Weight } \\
\text { (g) }\end{array}$ & $\begin{array}{c}\text { Weight } \\
(\%)\end{array}$ & MNI & $\begin{array}{l}\text { MNI } \\
(\%)\end{array}$ & $\begin{array}{c}\text { Weight } \\
\text { (g) }\end{array}$ & $\begin{array}{c}\text { Weight } \\
(\%)\end{array}$ \\
\hline 1 & 2.9 & 868 & 8328 & 680 & 78 & 8000 & 96 & 155 & 18 & 253 & 3 & 34 & 4 & 75 & 0.90 \\
\hline 2 & 8.1 & 1714 & 16549 & 1341 & 78 & 16000 & 97 & 316 & 18 & 482 & 3 & 58 & 3 & 67 & 0.41 \\
\hline 3 & 12.9 & 2379 & 27670 & 2136 & 90 & 27000 & 98 & 187 & 8 & 578 & 2 & 57 & 2 & 92 & 0.33 \\
\hline 4 & 18.2 & 2021 & 24716 & 1832 & 91 & 24129 & 98 & 147 & 7 & 529 & 2 & 43 & 2 & 58 & 0.24 \\
\hline 5 & 23.1 & 2682 & 30481 & 2392 & 89 & 29704 & 97 & 198 & 7 & 651 & 2 & 93 & 3 & 126 & 0.41 \\
\hline 6 & 27.7 & 2689 & 27166 & 2348 & 87 & 26254 & 97 & 286 & 11 & 822 & 3 & 55 & 2 & 90 & 0.33 \\
\hline 7 & 33.0 & 2439 & 26157 & 2131 & 87 & 25417 & 97 & 256 & 10 & 632 & 2 & 53 & 2 & 108 & 0.41 \\
\hline 8 & 36.3 & 980 & 9737 & 908 & 93 & 9525 & 98 & 54 & 6 & 138 & 1 & 18 & 2 & 74 & 0.76 \\
\hline 9 & 39.5 & 2386 & 26832 & 2139 & 90 & 26045 & 97 & 186 & 8 & 513 & 2 & 62 & 3 & 274 & 1.02 \\
\hline 10 & 44.9 & 2632 & 28283 & 2037 & 77 & 25952 & 92 & 545 & 21 & 2053 & 7 & 50 & 2 & 278 & 0.98 \\
\hline 11 & 50.8 & 3148 & 35944 & 2367 & 75 & 32909 & 92 & 712 & 23 & 2607 & 7 & 69 & 2 & 428 & 1.19 \\
\hline 12 & 56.4 & 2778 & 33627 & 2015 & 73 & 30148 & 90 & 697 & 25 & 2708 & 8 & 66 & 2 & 771 & 2.29 \\
\hline 13 & 60.6 & 1574 & 16636 & 1207 & 77 & 15330 & 92 & 328 & 21 & 1032 & 6 & 40 & 3 & 274 & 1.65 \\
\hline 14 & 65.6 & 2049 & 18309 & 1518 & 74 & 16662 & 91 & 474 & 23 & 1330 & 7 & 58 & 3 & 317 & 1.73 \\
\hline 15 & 70.6 & 1134 & 9299 & 858 & 76 & 8416 & 91 & 230 & 20 & 749 & 8 & 46 & 4 & 134 & 1.44 \\
\hline 16 & 75.3 & 1543 & 15701 & 1363 & 88 & 15145 & 96 & 114 & 7 & 246 & 2 & 67 & 4 & 310 & 1.97 \\
\hline 17 & 79.5 & 1583 & 14453 & 1510 & 95 & 14257 & 99 & 44 & 3 & 107 & 1 & 29 & 2 & 89 & 0.62 \\
\hline 18 & 84.5 & 2528 & 17384 & 2074 & 82 & 15857 & 91 & 403 & 16 & 1281 & 7 & 51 & 2 & 246 & 1.41 \\
\hline 19 & 89.6 & 1727 & 9914 & 972 & 56 & 7736 & 78 & 685 & 40 & 1778 & 18 & 70 & 4 & 400 & 4.03 \\
\hline 20 & 93.8 & 1633 & 11307 & 825 & 51 & 8699 & 77 & 573 & 35 & 1601 & 14 & 235 & 14 & 1007 & 8.90 \\
\hline 21 & 99.4 & 564 & 3465 & 413 & 73 & 3184 & 92 & 129 & 23 & 212 & 6 & 22 & 4 & 69 & 1.98 \\
\hline 22 & 104.6 & 174 & 917 & 90 & 52 & 695 & 76 & 77 & 44 & 162 & 18 & 7 & 4 & 60 & 6.54 \\
\hline 23 & 109.1 & 38 & 260 & 17 & 44 & 110 & 42 & 10 & 27 & 26 & 10 & 11 & 29 & 124 & 47.59 \\
\hline 24 & 116.1 & - & - & - & - & - & & - & - & & & - & - & - & - \\
\hline
\end{tabular}


Table 4. Non-molluscan faunal remains, SM:93.

\begin{tabular}{|c|c|c|c|c|c|c|}
\hline XU & $\begin{array}{c}\text { XU Weight } \\
(\mathbf{k g})\end{array}$ & $\begin{array}{c}\text { Bone } \\
(\#)\end{array}$ & $\begin{array}{c}\text { Bone Weight } \\
(\mathbf{g})\end{array}$ & $\begin{array}{c}\text { Crab Weight } \\
(\mathbf{g})\end{array}$ & $\begin{array}{c}\text { Otoliths } \\
(\#)\end{array}$ & $\begin{array}{c}\text { Combined Bone/Crab } \\
(\mathbf{g} / \mathbf{k g})\end{array}$ \\
\hline 1 & 41.9 & - & - & - & - & - \\
\hline 2 & 48.2 & 4 & 3.4 & - & - & 0.07 \\
\hline 3 & 50.7 & 4 & 1.5 & - & - & 0.03 \\
\hline 4 & 35.2 & 2 & 10.0 & - & - & 0.03 \\
\hline 5 & 39.7 & 3 & 1.5 & - & - & 0.04 \\
\hline 6 & 42.7 & 5 & 6.0 & 1.00 & - & 0.03 \\
\hline 7 & 36.4 & 3 & 1.0 & 0.03 & - & - \\
\hline 8 & 12.4 & - & - & - & - & 0.01 \\
\hline 9 & 36.0 & - & - & - & - & 0.11 \\
\hline 10 & 37.0 & - & - & 0.50 & - & 0.01 \\
\hline 11 & 43.0 & 4 & 5.0 & - & - & 0.06 \\
\hline 12 & 46.9 & 1 & 0.1 & 0.50 & - & 0.04 \\
\hline 13 & 35.7 & 17 & 6.0 & - & - & 0.00 \\
\hline 14 & 50.7 & 12 & 2.0 & 1.00 & 1 & - \\
\hline 15 & 37.2 & 2 & 1.5 & - & - & 0.01 \\
\hline 16 & 46.4 & 2 & 0.1 & - & - & 0.07 \\
\hline 17 & 33.0 & - & - & - & - & 0.06 \\
\hline 18 & 46.0 & 1 & 0.5 & - & - & - \\
\hline 19 & 43.6 & 6 & 3.0 & - & - & - \\
\hline 20 & 50.4 & - & - & 3.00 & - & - \\
\hline 21 & 49.2 & 4 & 1.5 & - & - & - \\
\hline 22 & 41.0 & - & - & - & - & - \\
\hline 23 & 41.9 & - & - & - & - & - \\
\hline 24 & 87.9 & - & - & - & - & $\mathbf{1}$ \\
\hline TOTAL & $\mathbf{1 0 3 3 . 1}$ & $\mathbf{7 0}$ & $\mathbf{3 4 . 1}$ & $\mathbf{6 . 0 3}$ & $\mathbf{1}$ & \\
\hline & & & & & & - \\
\hline
\end{tabular}

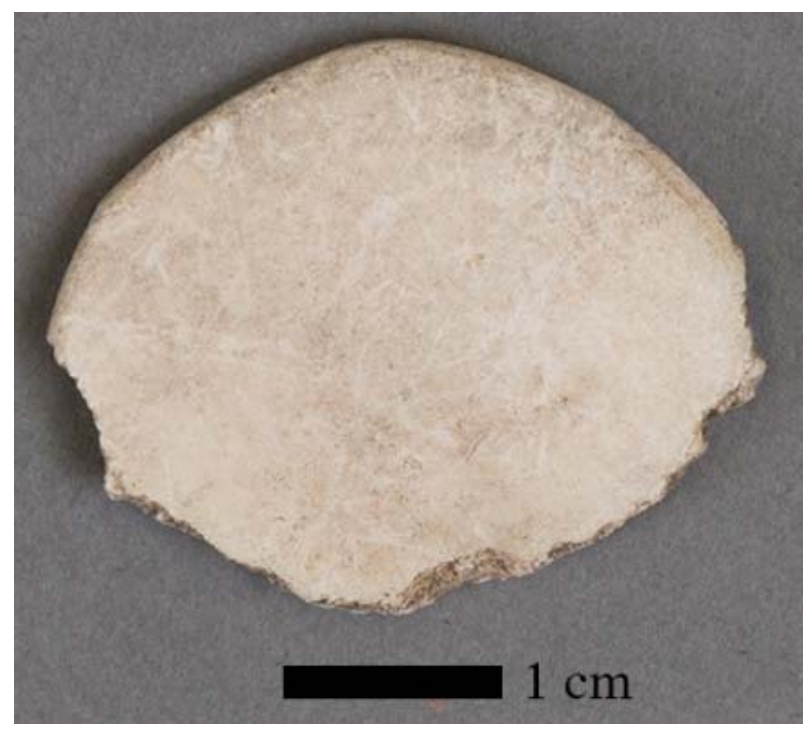

Figure 9. Shell artefact 1, SM:93.

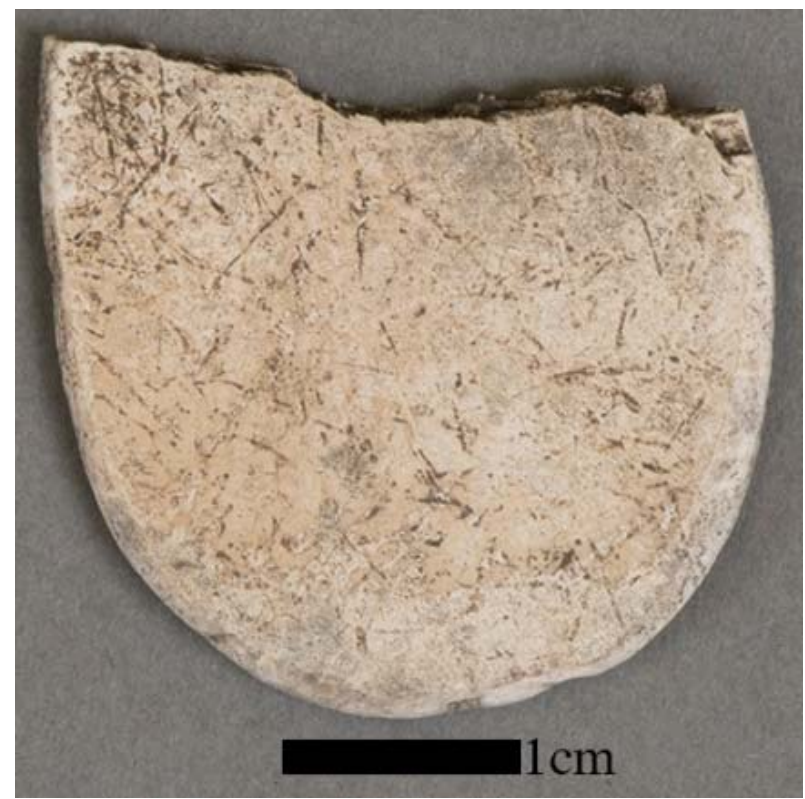

Figure 10. Shell artefact 2, SM:93. 
Table 5. Summary data, SM:91.

\begin{tabular}{|c|c|c|c|c|c|c|c|}
\hline XU & $\begin{array}{c}\text { Mean Depth } \\
(\mathbf{c m})\end{array}$ & $\begin{array}{c}\text { Gross Weight } \\
\mathbf{( g )}\end{array}$ & $\begin{array}{c}\mathbf{6 m m} \text { Residue } \\
\mathbf{( g )}\end{array}$ & $\begin{array}{c}\mathbf{2 m m} \\
\text { Residue } \\
\mathbf{( g )}\end{array}$ & $\begin{array}{c}\text { Soil } \\
\mathbf{( g )}\end{array}$ & $\begin{array}{c}\text { Charcoal } \\
\mathbf{( g )}\end{array}$ & $\begin{array}{c}\text { Stones/ } \\
\text { Rocks (g) }\end{array}$ \\
\hline 1 & 4.2 & 11500 & 4811 & 3000 & 3689 & 1 & 260 \\
\hline 2 & 3.35 & 13000 & 4932 & 2500 & 5568 & 1 & 365 \\
\hline 3 & 3.6 & 13000 & 4637 & 2500 & 5863 & 3 & 230 \\
\hline 4 & 4.25 & 15000 & 4673 & 2500 & 7827 & 5 & 205 \\
\hline 5 & 2.8 & 12500 & 3001 & 3000 & 6499 & 2 & 295 \\
\hline 6 & 4.5 & 14250 & 3384 & 2500 & 8366 & 2 & 395 \\
\hline 7 & 3.4 & 13000 & 3062 & 2000 & 7938 & 1 & 370 \\
\hline 8 & 4.75 & 16500 & 4026 & 4000 & 8474 & 0 & 475 \\
\hline
\end{tabular}

$25 \%$ ) and $19-23(22-44 \%)$. The contribution of all other species to the composition of the site is less than $10 \%$ for all but two XUs where they represent 14\% (XU20) and $29 \%$ (XU23) of the total shellfish MNI. This correlates with a dramatic reduction in overall shellfish MNI and weights. The proportions of other species in the deposit vary but most frequently included $S$. cucullata, Polymesoda erosa, Nerita lineata, Telescopium telescopium, Volema cochlidium, Melo spp., Balanus spp., Cerithium spp., Ellobium spp. and Terebralia spp.

A restricted range of other faunal remains were recovered in the $6 \mathrm{~mm}$ sieve residues (Table 4 ). These included fragments of mammal bone, as well as occasional crab claw fragments and a single fish otolith. Two cranial skeletal elements were recovered in the excavation including a small fragment of a mandible and a small piece of tooth. Identification was not attempted on these because of their small size and incomplete state, although the mandible fragment is likely to be that of a macropod (Matthew McDowell, pers. comm., 2014). A total of 63 post-cranial bone fragments were recovered. These were all very small and generally less than $10 \mathrm{~mm}$ in length. Bone materials recovered in the excavation weighed less than $34 \mathrm{~g}$ in total for all pits combined. The crab claw fragments were very small, with often only the claw tip being identified, and are tentatively identified as Scylla spp., though precise identification is not possible due to their small, fragmented nature. These amounted to around $5 \mathrm{~g}$ for the entire excavation. The single fish otolith was $12 \mathrm{~mm}$ in diameter and identification is not likely to be possible due to its fragile and damaged condition.

A small number of shell and stone artefacts were recovered in SM:93. These included three small quartz fragments, the largest measuring a maximum of $21 \mathrm{~mm}$ in length and $12 \mathrm{~mm}$ in width. All were highly angular with few clear diagnostic attributes. In addition, two distinctive shell artefacts were recovered, one each from XUs 9 and 10. Both items are less $2-3 \mathrm{~mm}$ thick, flat pieces of an unknown species of shell $30 \mathrm{~mm}$ by $27 \mathrm{~mm}$ and $32 \mathrm{~mm}$ by $26 \mathrm{~mm}$ in size respectively (Figures 9 and 10). Both are broken at one end and ground to form a smooth, rounded edge at the other.

\section{SM:91}

$\mathrm{SM}: 91$ is a small shell mound situated immediately to the north of SM:92 with a maximum height of $30 \mathrm{~cm}$ and up to $5 \mathrm{~m}$ in diameter on a sandy substrate containing frequent bauxite pisoliths and high proportions of shell, including $T$. granosa valves of a range of sizes, frequent fine shell hash and small species such as Cerithium spp. (Tables 5 and 6). This is likely due to the exposed location in which SM:91 occurs: unlike other sites at Prunung, no vegetation buffer occurs between it and the active beach which is approximately $30 \mathrm{~m}$ away.

A single $0.5 \mathrm{~m}^{2}$ test pit was excavated on the highest part of the SM:91 mound surface. Approximately $35 \mathrm{~cm}$ of shell-dominated deposit was excavated before reaching sandy deposits containing little to no shell. The stratigraphy consisted of a $3-5 \mathrm{~cm}$ upper layer (A) comprising whole and fragmented shell with moderate proportions of dark humic soil. Sand and bauxite pisoliths occurred in moderate proportions within this upper layer. A second layer (B) up to $18 \mathrm{~cm}$ in depth consisted of densely packed $T$. granosa valves $3-5 \mathrm{~cm}$ in length. Small numbers of bauxite pisoliths occurred here along with small proportions of light sand. The basal layer (C) consisted of yellow to orange coloured sand with frequent bauxite nodules and low proportions of shell. This latter layer was interpreted as culturally sterile due to the low proportions of shell and their more fragmented nature.

A single sample of $T$. granosa valves were retrieved from the interface between Layers B and C, approximating the lowest level of shell deposit. The resulting determination of $469 \pm 43 \mathrm{BP}$ (Wk13788) was found to be modern when calibrated (Table 1).

One hundred percent of the T. granosa and a sub-sample (25-50\%) of the remaining $6 \mathrm{~mm}$ sieve residues were quantified (Strategy B in Morrison 2013b). T. granosa is the most frequently occurring shellfish species across all XUs at SM:91 representing $38-61 \%$ by MNI (Table 6, Figure 11). S. cucullata and Cerithium spp. are the next most frequently occurring species, with the former representing $10-18 \%$ of the MNI in the upper four XUs, and the latter species most frequent at $17-42 \%$ in the lower XUs. Cerithium spp. are a small gastropod generally $<15 \mathrm{~mm}$ in length which commonly inhabit intertidal flats. Their presence in reasonable numbers is of significance and considered here to reflect the influence of storm surges washing over this very low, exposed site. They are also commonly located in naturally formed beach ridge deposits at Prunung, and the high proportions of Cerithium spp. in XUs 6, 7 and 8 likely reflect intermixing of anthropogenic shell with the underlying natural substrate.

Only a small amount of non-molluscan faunal material was recovered in the $6 \mathrm{~mm}$ residues from SM:91 (Table 7). This included a total of $2 \mathrm{~g}$ of crab fragments and $3 \mathrm{~g}$ of 
Table 6. Shellfish quantification data, SM91. * All T. granosa valves for each XU quantified. MNI and weight values are the unmodified figures. Adjusted MNI and weight (rows 7-10) are adjusted to reflect the overall sample size subject to systematic quantification in the laboratory (percentage values in row 2). All other shellfish weights and MNI data based on counts of the sample investigated in the lab (i.e. rows 1 and 2).

\begin{tabular}{|c|c|c|c|c|c|c|c|c|c|}
\hline $\mathbf{X U}$ & & XU1 & XU2 & XU3 & XU4 & XU5 & XU6 & XU7 & XU8 \\
\hline \multirow{4}{*}{$\begin{array}{c}\text { Sample } \\
\text { Information }\end{array}$} & Sample weight & 773 & 939 & 698 & 670 & 516 & 650 & 514 & 669 \\
\hline & Sample $\%$ of total & 27.93 & 29.19 & 25.24 & 25.95 & 27.80 & 27.45 & 25.02 & 25.59 \\
\hline & $\begin{array}{r}\text { Combined shellfish MNI - } \\
\text { Sample }\end{array}$ & 68.39 & 87.47 & 51.68 & 61.26 & 46.94 & 63.29 & 48.77 & 84.84 \\
\hline & $\begin{array}{l}\text { Combined diagnostic } \\
\text { shellfish weight - Sample }\end{array}$ & 702.53 & 666.59 & 574.57 & 666.57 & 379.33 & 361.89 & 290.25 & 390.37 \\
\hline \multirow{6}{*}{$\begin{array}{c}\text { Tegillarca } \\
\text { granosa* }\end{array}$} & MNI & 150 & 133.5 & 123.5 & 145.5 & 100.5 & 88.5 & 97 & 142 \\
\hline & Weight & 2043 & 1715 & 1872 & 2089 & 1145 & 1016 & 1008 & 1412 \\
\hline & Adjusted MNI & 41.89 & 38.97 & 31.18 & 37.76 & 27.94 & 24.29 & 24.27 & 36.34 \\
\hline & Adjusted MNI \% & 61.25 & 44.55 & 60.33 & 61.64 & 59.52 & 38.38 & 49.77 & 42.83 \\
\hline & Adjusted Weight & 570.53 & 500.59 & 472.57 & 542.07 & 318.33 & 278.89 & 252.25 & 361.37 \\
\hline & Adjusted Weight \% & 81.21 & 75.10 & 82.25 & 81.32 & 83.92 & 77.06 & 86.91 & 92.57 \\
\hline \multirow{4}{*}{$\begin{array}{l}\text { Saccostrea } \\
\text { cucullata }\end{array}$} & MNI & 12.5 & 12 & 9.5 & 9.5 & 5 & 1.5 & 0 & 1.5 \\
\hline & MNI \% & 18.28 & 13.72 & 18.38 & 15.51 & 10.65 & 2.37 & 0.00 & 1.77 \\
\hline & Weight & 100 & 125 & 70 & 85 & 47 & 5 & 0 & 2 \\
\hline & Weight $\%$ & 14.23 & 18.75 & 12.18 & 12.75 & 12.39 & 1.38 & 0.00 & 0.51 \\
\hline \multirow{4}{*}{ Cerithiidae } & MNI & 8 & 31 & 5 & 6 & 8 & 18 & 13 & 36 \\
\hline & MNI \% & 11.70 & 35.44 & 9.68 & 9.80 & 17.04 & 28.44 & 26.65 & 42.43 \\
\hline & Weight & 2 & 6 & 1 & 2 & 2 & 3 & 3 & 7 \\
\hline & Weight $\%$ & 0.28 & 0.90 & 0.17 & 0.30 & 0.53 & 0.83 & 1.03 & 1.79 \\
\hline \multirow{4}{*}{$\begin{array}{l}\text { All other } \\
\text { species }\end{array}$} & MNI & 6 & 5.5 & 6 & 8 & 6 & 19.5 & 11.5 & 11 \\
\hline & MNI \% & 8.77 & 6.29 & 11.61 & 13.06 & 12.78 & 30.81 & 23.58 & 12.97 \\
\hline & Weight & 30 & 35 & 31 & 37.5 & 12 & 75 & 35 & 20 \\
\hline & Weight \% & 4.27 & 5.25 & 5.40 & 5.63 & 3.16 & 20.72 & 12.06 & 5.12 \\
\hline
\end{tabular}

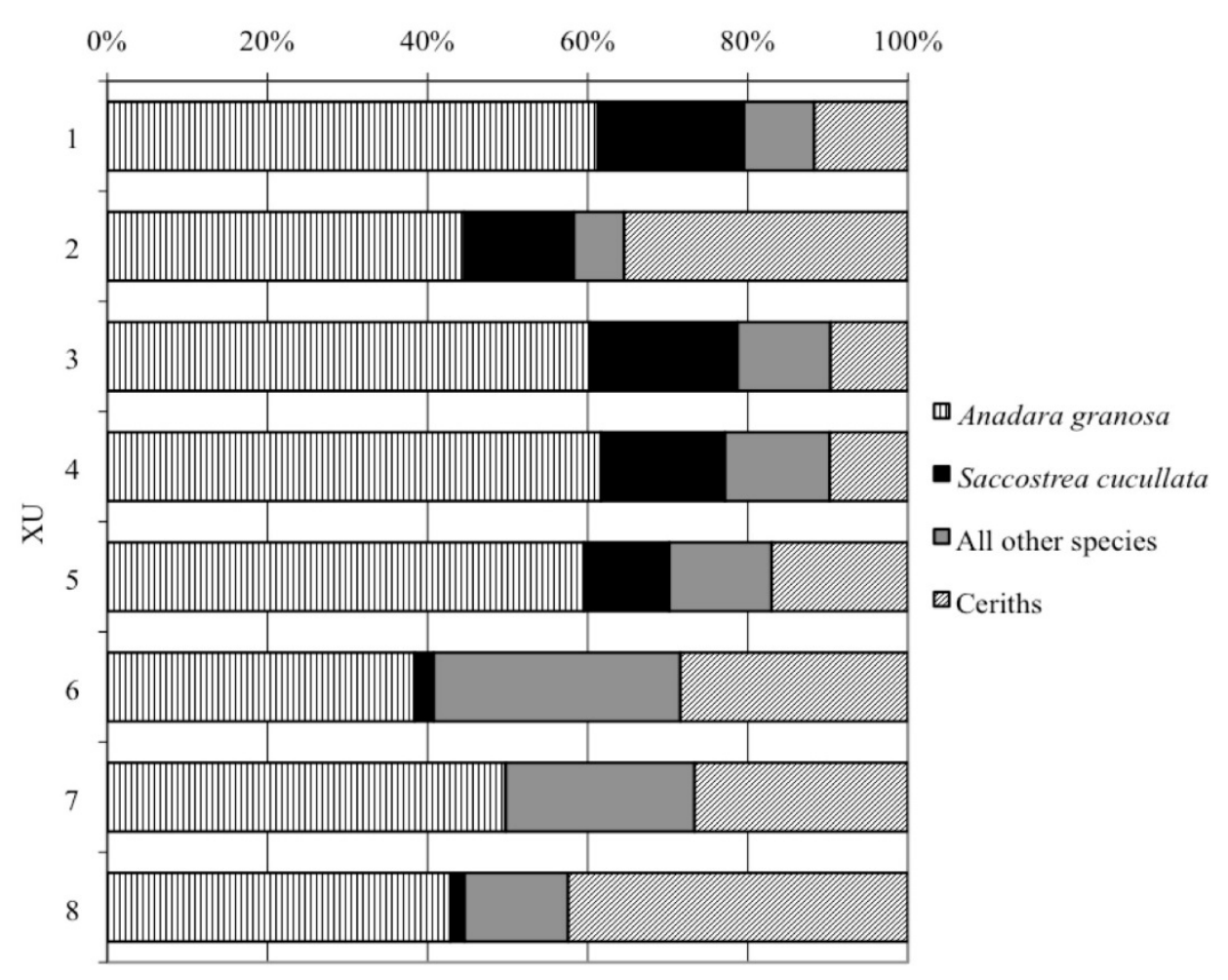

Figure 11. Shellfish MNI data, SM:91. 
Table 7. Non-molluscan faunal materials, SM:91.

\begin{tabular}{|c|cc|c|}
\hline XU & $\begin{array}{c}\text { Crab Fragments } \\
\text { (g) }\end{array}$ & $\begin{array}{c}\text { Other Bone } \\
\text { (g) }\end{array}$ \\
\hline 1 & - & - \\
\hline 2 & - & 1 & 0.5 \\
\hline 3 & & 1 & 1.5 \\
\hline 4 & & & - \\
\hline 5 & - & - \\
\hline 6 & - & - \\
\hline 7 & - & - \\
\hline 8 & - & \multicolumn{2}{|c|}{3} \\
\hline Total & \multicolumn{2}{|c|}{} \\
\hline
\end{tabular}

Table 8. Artefacts, SM:91.

\begin{tabular}{|c|l|l|r|r|r|r|}
\hline XU & Raw Material & Type & \multicolumn{1}{c|}{$\begin{array}{c}\text { Cortex } \\
(\mathbf{\%})\end{array}$} & $\begin{array}{c}\text { Length } \\
(\mathbf{m m})\end{array}$ & \multicolumn{1}{|c|}{$\begin{array}{c}\text { Width } \\
(\mathbf{m m})\end{array}$} & \multicolumn{1}{c|}{$\begin{array}{c}\text { Thickness } \\
(\mathbf{m m})\end{array}$} \\
\hline 1 & Silcrete & Broken flake & $1-50$ & 35 & 19 & 10 \\
\hline 5 & Green Glass & Flake & na & 13 & 9 & 2.6 \\
\hline
\end{tabular}

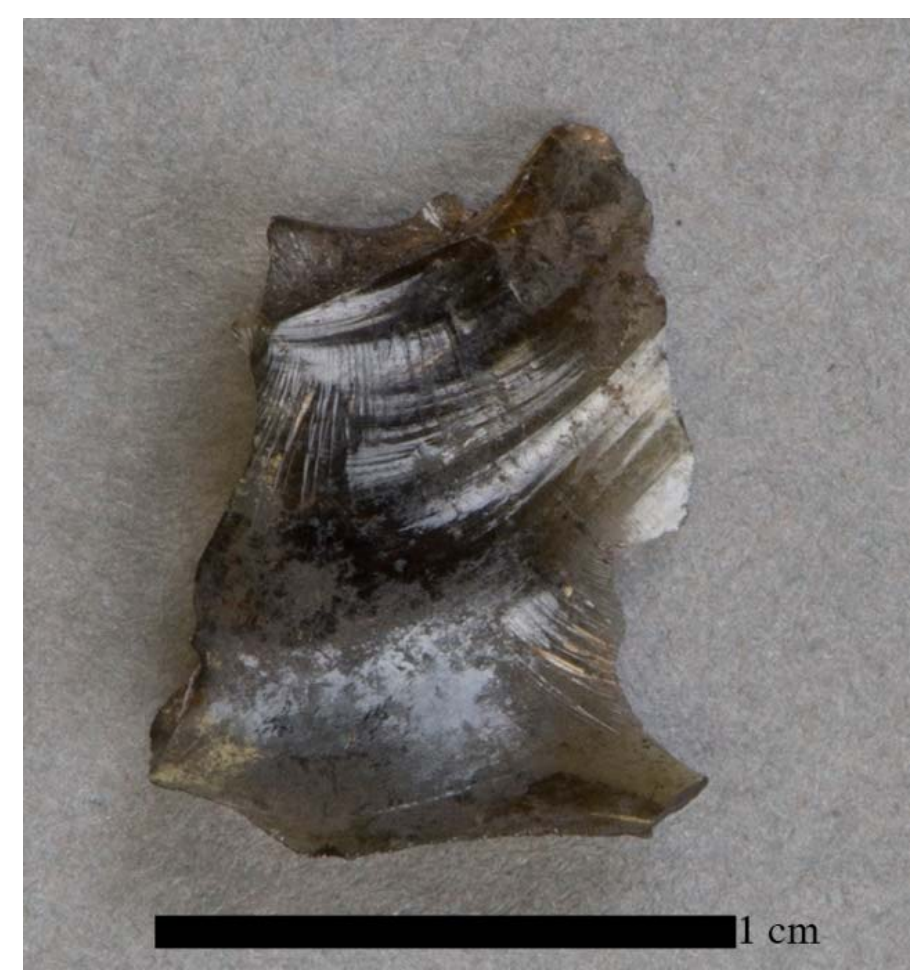

Figure 12. Glass artefact recovered from SM:91, XU5. 
small non-diagnostic bone fragments, both recovered in XUs 2-4. Two artefacts were recovered in SM:91 (Table 8): the first was a small broken silcrete flake recovered near the surface in XU1 and the second was a small fragment of green glass $13 \mathrm{~mm}$ in length recovered from XU5 (Layer B), $16-18 \mathrm{~cm}$ below surface. A series of eraillure scars suggest this may be a small piece of debitage (Figure 12).

\section{SM:92}

SM:92 is an elongated shell mound that is part of the primary group of sites at Prunung Point. The site is $30 \mathrm{~m}$ long, $10 \mathrm{~m}$ wide, and up to $1.4 \mathrm{~m}$ in height and is situated immediately to the northeast of SM:93 (Figure 2). Excavations at this site aimed to obtain an indicative radiocarbon determination for the basal deposits while causing minimal disturbance to the site. To this end, a small $30 \mathrm{~cm} \times 30 \mathrm{~cm}$ pit was excavated to a depth of $75 \mathrm{~cm}$ below surface.

The site had a $5-10 \mathrm{~cm}$ upper layer of fragmented shell, principally $T$. granosa, with a matrix of fine sediment and dense roots, beneath which a $\sim 50 \mathrm{~cm}$ layer of mostly whole T. granosa shell with little sediment occurred. The underlying basal layer contained more sediment and ashy deposit, but shellfish was nevertheless the dominant constituent. The substrate on which the deposit occurred consisted of fine yellow to orange coloured sand with essentially no shell hash or other shell.

A single sample of T. granosa valves retrieved from the basal cultural layer of SM:92 returned an age span of 518649 cal BP (Wk-14507) (Table 1).

\section{SM:90}

SM:90 is a slightly elongated shell mound $28 \mathrm{~m}$ long, $15 \mathrm{~m}$ wide and up to $70 \mathrm{~cm}$ in height. It is located at the northeastern end of the primary complex of shell mounds (Figure 2). Work on this site aimed to obtain a sample suitable for radiocarbon dating with minimal disturbance to the site. A $30 \mathrm{~cm} \times 30 \mathrm{~cm}$ pit was excavated on its seaward flank to a depth of $55 \mathrm{~cm}$.

The stratigraphy of SM:90 consisted of a $15 \mathrm{~cm}$ upper layer of highly fragmented shell, principally T. granosa, in a matrix of dark organic soil. Below this, a $30 \mathrm{~cm}$ layer of whole and fragmented shell occurred; this contained little soil or sediment and consisted of large proportions of $T$. granosa valves that had a relatively 'clean' appearance compared with the overlaying deposits. The basal layer was less than $10 \mathrm{~cm}$ in depth and consisted of whole and fragmented shell, ashy sediment and frequent fine sand with occasional bauxite pisoliths. The underlying substrate consisted of fine beach sand with moderate proportions of bauxite pisoliths.

A single sample of $T$. granosa valves from the basal cultural layer of SM:90 returned a calibrated age span of 559-708 cal BP (Wk14506).

Brief field inspections indicated that the composition of SM:90 was predominantly T. granosa. Moderate proportions of $M$. hiantina were also recovered, along with occasional $P$. erosa, $N$. lineata and $V$. cochlidium. No detailed quantification work was carried out on these samples. Preliminary investigation of SM:90 suggests this is a cultural deposit dominated by large proportions of $T$. granosa valves. The anthropogenic deposit is distinct in relation to the underlying substrate, which consists of large proportions of fine beach sand, bauxite pisoliths and infrequent fragmented shell.

\section{SM:86}

$\mathrm{SM}: 86$ is a $50 \mathrm{~cm}$ high mound with maximum basal dimensions of $15 \mathrm{~m} \mathrm{x} 25 \mathrm{~m}$ located approximately $1 \mathrm{~km}$ directly west of SM:96 (Figure 2) on sandy sediments containing large numbers of bauxite pisoliths and infrequent shell. The area in which SM:86 occurs is unique in the Prunung study area because of the occurrence of a slight promontory comprised of hard bauxite pisoliths and ironstone conglomerate pavement. This pavement slopes gently downward from the flat, sandy dune substrates approximately $1.5 \mathrm{~m}$ above water level to the mudflats exposed at low tides. This pavement has restricted mangrove growth on either side of SM:86 and therefore provides a natural access point through the mangroves to the mudflats.

A single $50 \mathrm{~cm}^{2}$ square test pit was excavated $48 \mathrm{~cm}$ through the mound deposit and into the underlying sandy substrates (Table 9). Excavated 6mm samples for XUs 5 and 6 are unavailable for analysis because these along with some less crucial soil and sediment samples were lost while being transported by a freight company from Weipa to Townsville (Table 9). Data on these units are therefore omitted here. The stratigraphy of SM:86 consisted of two distinct layers with the upper layer (A) consisting of loosely-packed shell interspersed with dark sandy matrix. This was up to $35 \mathrm{~cm}$ in depth and numerous small roots and rootlets occurred throughout. A single large root 6$10 \mathrm{~cm}$ in diameter was removed from the northern portion of the square in this layer. Whole and fragmented $T$. granosa valves were the primary shellfish species observed in the section. The second layer (B) was up to $20 \mathrm{~cm}$ in depth and consisted of compact yellowish sand with infrequent shellfish. Occasional fine rootlets also occurred. A distinct intrusion of primarily T. granosa shell occurred in the southern portion of the square (C) and this was up to $5 \mathrm{~cm}$ in depth and $14 \mathrm{~cm}$ long. A single sample of T. granosa valves were obtained from the basal layer of SM:86 and returned a calibrated age span of 381-539 cal BP (Wk13787).

Sampling strategy B was used on XUs 1-3 to minimise the need to remove cultural deposits (see Morrison 2013b). All other XUs were fully analysed. Shellfish remains were the primary cultural material recovered in the site and quantification of available $6 \mathrm{~mm}$ samples from SM:86 (Table 10, Figure 13) indicate that T. granosa compromises between $44 \%$ and $98 \%$ of overall MNI. $M$. hiantina is the next most frequently occurring species, ranging from 5 to $52 \%$ of each XU's total MNI. The proportions of $M$. hiantina increase over time and are present in greater proportions than $T$. granosa in XU1. Other species frequently represented included $S$. cucullata, $N$. lineata and $V$. cochlidium. Several Balanus spp. fragments were also recovered.

\section{SM:88}

$\mathrm{SM}: 88$ is a dome-shaped shell mound deposit up to $75 \mathrm{~cm}$ high with a maximum basal diameter of $18 \mathrm{~m}$ that is located approximately $450 \mathrm{~m}$ south of the contemporary shoreline and $800 \mathrm{~m}$ northwest of the main group of shell mounds at Prunung Point (Figure 2). The site occurs on a 
Table 9. Summary data, SM86. Darkened cells represent samples lost during transport as discussed in text. XUs 1-3 were quantified with sampling strategy B. Other XUs were fully analysed.

\begin{tabular}{|c|c|c|c|c|c|c|c|c|c|c|c|}
\hline $\mathbf{X U}$ & 1 & 2 & 3 & 4 & 5 & 6 & 7 & 8 & 9 & 10 & 11 \\
\hline Mean Depth $(\mathrm{cm})$ & 6 & 2.65 & 6.3 & 5.7 & 3.6 & 2.6 & 2.7 & 3.2 & 3.4 & 4.4 & 7.5 \\
\hline Gross Weight (g) & 10000 & 11500 & 10500 & 8500 & 9500 & 9000 & 10000 & 9500 & 13300 & 15000 & 16000 \\
\hline 6mm Residue (g) & 4840 & 5783 & 4590 & 3970 & & & 4457 & 4177 & 3036 & 1183 & 1038 \\
\hline 2mm Residue (g) & 2500 & 3500 & 3500 & 3500 & 3000 & 3500 & 700 & 200 & 400 & 500 & 3600 \\
\hline Soil (g) & 2660 & 2217 & 2410 & 1030 & 6500 & 5500 & 4843 & 5123 & 9864 & 13317 & 11362 \\
\hline Stones/Rocks (g) & 8 & 10 & 5 & 18 & & & 2 & 2 & 14 & 20 & 65 \\
\hline Charcoal (g) & 4 & 8 & 5 & 12 & & & 5 & 5 & 3 & 3 & 2 \\
\hline
\end{tabular}

Table 10. Shellfish quantification data, SM:86. Note: $6 \mathrm{~mm}$ residues for XUs 5 and 6 were not available for analysis.

\begin{tabular}{|c|c|c|c|c|c|c|c|c|c|c|}
\hline & & XU1 & XU2 & XU3 & XU4 & XU7 & XU8 & XU9 & XU10 & XU11 \\
\hline \multirow{4}{*}{$\begin{array}{c}\text { Sample } \\
\text { Information }\end{array}$} & Sample weight & 795.0 & 489.0 & 243.0 & 521.0 & 565.0 & 269.0 & 387.0 & 400.0 & - \\
\hline & Sample $\%$ of total & 26.6 & 28.0 & 25.2 & 100.0 & 100.0 & 100.0 & 100.0 & 100.0 & 100.0 \\
\hline & Total MNI - Sample & 90.4 & 121.2 & 84.8 & 256.0 & 420.5 & 497.5 & 378.0 & 103.5 & 5.5 \\
\hline & $\begin{array}{l}\text { Total Weight - } \\
\text { Sample }\end{array}$ & 579.0 & 1207.8 & 977.5 & 3539.8 & 4034.0 & 3950.0 & 2699.0 & 853.5 & 15.0 \\
\hline \multirow{6}{*}{$\begin{array}{c}\text { Tegillarca } \\
\text { granosa }\end{array}$} & MNI (Actual) & 152.0 & 292.0 & 239.0 & 226.0 & 395.5 & 488.0 & 361.5 & 85.0 & - \\
\hline & Weight (Actual) & 1848.0 & 4035.0 & 3627.0 & 3449.0 & 3892.0 & 3908.0 & 2649.0 & 783.0 & - \\
\hline & Adjusted MNI & 40.4 & 81.7 & 60.3 & 226.0 & 395.5 & 488.0 & 361.5 & 85.0 & - \\
\hline & Adjusted MNI \% & 44.7 & 67.4 & 71.1 & 88.3 & 94.1 & 98.1 & 95.6 & 82.1 & - \\
\hline & Adjusted Weight & 491.0 & 1128.8 & 915.2 & 3449.0 & 3892.0 & 3908.0 & 2649.0 & 783.0 & - \\
\hline & Adjusted Weight \% & 84.8 & 93.5 & 93.6 & 97.4 & 96.5 & 98.9 & 98.1 & 91.7 & - \\
\hline \multirow{4}{*}{$\begin{array}{c}\text { Marcia } \\
\text { hiantina }\end{array}$} & MNI & 47.0 & 27.5 & 17.5 & 23.5 & 20.5 & 8.0 & 11.5 & 17.5 & 5.5 \\
\hline & MNI \% & 52.0 & 22.7 & 20.6 & 9.2 & 4.9 & 1.6 & 3.0 & 16.9 & 100.0 \\
\hline & Weight & 80.0 & 60.0 & 55.0 & 80.0 & 70.0 & 20.0 & 20.0 & 70.0 & 15.0 \\
\hline & Weight $\%$ & 13.8 & 5.0 & 5.6 & 2.3 & 1.7 & 0.5 & 0.7 & 8.2 & 100.0 \\
\hline \multirow{4}{*}{$\begin{array}{l}\text { All other } \\
\text { species }\end{array}$} & MNI & 3.0 & 12.0 & 7.0 & 6.5 & 4.5 & 1.5 & 5.0 & 1.0 & - \\
\hline & MNI \% & 3.3 & 9.9 & 8.3 & 2.5 & 1.1 & 0.3 & 1.3 & 1.0 & - \\
\hline & Weight & 8.0 & 19.0 & 7.3 & 10.8 & 72.0 & 22.0 & 30.0 & 0.5 & - \\
\hline & Weight $\%$ & 1.4 & 1.6 & 0.7 & 0.3 & 1.8 & 0.6 & 1.1 & 0.1 & - \\
\hline
\end{tabular}




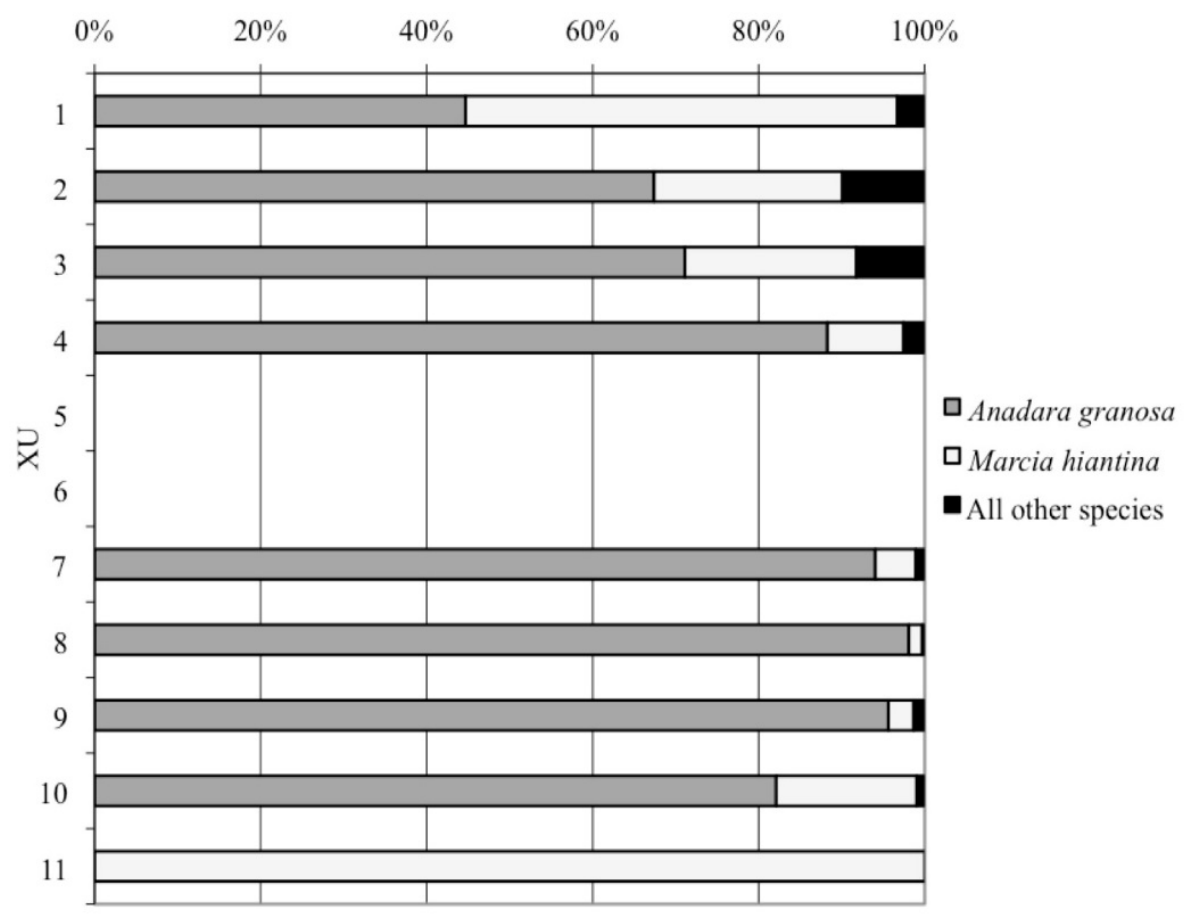

Figure 13. Shellfish MNI data, SM:86.

narrow sand ridge between the margin of the bauxite plateau and the inland limits of a seasonal swamp. Much of the surrounding area becomes inundated during the wet season. A large $2 \mathrm{~m} \times 2 \mathrm{~m}$ depression occurs approximately $10 \mathrm{~m}$ to the north of SM:88 and has been constructed in recent times, probably for use as a well after the 1960 s (Richard Barkley, pers. comm., 2004). A 3m x 4m area of deposit has been removed from the shell mound through quarrying, however, the remaining deposit appeared undisturbed. The site's unusual location away from the coast meant that it was a priority for investigation and so a $50 \mathrm{~cm}^{2}$ test pit was excavated on an undisturbed portion of the site to approximately $70 \mathrm{~cm}$ below surface.

The stratigraphy of SM: 88 consisted of three broad layers. A $15 \mathrm{~cm}$ deep upper layer (A) was comprised of large proportions of mostly fragmented and whole $T$. granosa shell interspersed with dark humic materials and a dense layer of rootlets. Beneath this a further layer dominated by T. granosa shell occurred (B); this contained larger proportions of whole shell and high proportions of soil of a darker colour than in Layer A and was $45-50 \mathrm{~cm}$ deep. Layer B overlaid a layer of fine sandy sediments containing large proportions of bauxite pisoliths (C). Shell was infrequent, and these deposits are considered to be culturally sterile substrates. This layer was excavated to a depth of around $15 \mathrm{~cm}$ and shell proportions decreased with depth. Summary excavation data show a proportional increase in fine sediments in XU 7 (Table 11).

Two samples of $T$. granosa were collected for radiocarbon determinations. These were obtained from the interface between Layers A and B $(21 \mathrm{~cm} \mathrm{BS})$ and the interface between Layers B and C $(65 \mathrm{~cm}$ BS $)$, the base of the lower cultural layer. The basal determination returned a calibrated age span of 431-560 cal BP (Wk-14509). During the physical pretreatment stages the laboratory observed that the upper radiocarbon dating sample had undergone calcite recrystalisation. Aragonite was selected for dating and, due to the reduction in sample size, AMS measurement was required. The resulting determination was 289-463 cal BP (Wk-14508).

Sampling strategy B was used to calculate shellfish data for SM:88 and MNI data are based on subsamples of the $6 \mathrm{~mm}$ residues. These represented between $12 \%$ and $51 \%$ by weight of the $6 \mathrm{~mm}$ residues after diagnostic T. granosa had been removed (Table 12, Figure 14). M. hiantina was the dominant shellfish species across all XUs, though in many cases it occurred in only marginally greater proportions comprising $43-61 \%$ of each XU, while $T$. granosa variously comprises $27-48 \%$ by MNI. Other species comprise up to $14 \%$ by MNI in some XUs, and this is primarily due to the greater proportions of $V$. cochlidium and $S$. cucullata in some XUs: however, this is not consistent throughout all XUs.

Small numbers of crab, bone and otoliths were recovered in the excavation of SM:88 (Table 13). As noted above, all of the $6 \mathrm{~mm}$ samples were sorted in order to maximise chances of recovering these materials. While only one otolith was recovered in XU4, both crab fragments (typically small fragments of claw) and nondiagnostic bone were found consistently through XUs 2-5. No more than $5 \mathrm{~g}$ of bone and $5 \mathrm{~g}$ of crab were found in any one layer, and overall weights were $21 \mathrm{~g}$ for crab and $14 \mathrm{~g}$ for bone. Three stone artefacts were recovered from SM:88 (Table 14). A broken silcrete flake was recovered near the surface of XU1, a broken quartz flake recovered in XU2 and a small angular fragment of quartz was recovered in XU4. This is viewed here to be an artefact because quartz does not naturally occur in the surrounding sediments. No identifiable shell or bone artefacts were recovered.

\section{2mm Residue Sampling}

As with previous work at Bweening (Morrison 2013b), investigations of $2 \mathrm{~mm}$ residues at Prunung selectively targeted those XUs with the highest proportions of non- 
Table 11. Summary data, SM:88.

\begin{tabular}{|l|r|r|r|r|r|r|r|}
\hline & \multicolumn{1}{|c|}{ XU1 } & \multicolumn{1}{c|}{ XU2 } & \multicolumn{1}{c|}{ XU3 } & \multicolumn{1}{c|}{ XU4 } & \multicolumn{1}{c|}{ XU5 } & \multicolumn{1}{c|}{ XU6 } & \multicolumn{1}{c|}{ XU7 } \\
\hline Mean Depth (cm) & 7.27 & 11.78 & 11.95 & 10.22 & 9.23 & 9.52 & 7.28 \\
\hline Gross Weight (g) & 21700 & 24400 & 24500 & 24900 & 26000 & 27500 & 16000 \\
\hline 6mm Residue (g) & 9455 & 8601 & 8168 & 8555 & 9727 & 7012 & 3452 \\
\hline 2mm Residue (g) & 3000 & 3700 & 3500 & 3500 & 3400 & 2500 & 6500 \\
\hline Soil (g) & 9245 & 12099 & 12832 & 12845 & 12873 & 17988 & 6048 \\
\hline Stones and Rocks (g) & 495 & 205 & 130 & 130 & 400 & 405 & 655 \\
\hline
\end{tabular}

Table 12. Shellfish quantification data, SM:88.

\begin{tabular}{|c|c|c|c|c|c|c|c|c|}
\hline & & XU1 & XU2 & XU3 & XU4 & XU5 & XU6 & XU7 \\
\hline \multirow{4}{*}{$\begin{array}{c}\text { Sample } \\
\text { Information }\end{array}$} & Sample weight & 938 & 3260 & 2875 & 1439 & 1700 & 1852 & 818 \\
\hline & Sample $\%$ of total & 12.8 & 49.4 & 50.8 & 25.6 & 25.9 & 34.2 & 25.9 \\
\hline & Estimated total MNI & 67 & 286 & 306 & 177 & 207 & 210 & 26 \\
\hline & Estimated total Weight & 407 & 1461 & 1669 & 1019 & 1117 & 1072 & 140 \\
\hline \multirow{6}{*}{$\begin{array}{c}\text { Tegillarca } \\
\text { granosa }\end{array}$} & MNI (Actual) & 224 & 197 & 247 & 329 & 357 & 170 & 35 \\
\hline & Weight (Actual) & 2120 & 1998 & 2503 & 2939 & 3153 & 1604 & 288 \\
\hline & Adjusted MNI & 28.7 & 97.4 & 125.3 & 84.3 & 92.3 & 58.2 & 8.9 \\
\hline & Adj MNI \% & 42.7 & 34.0 & 41.0 & 47.7 & 44.5 & 27.8 & 34.4 \\
\hline & Adjusted Weight & 271.1 & 986.4 & 1270.3 & 753.1 & 815.3 & 549.3 & 74.5 \\
\hline & Adj Weight \% & 66.6 & 67.5 & 76.1 & 73.9 & 73.0 & 51.2 & 53.0 \\
\hline \multirow{4}{*}{$\begin{array}{c}\text { Marcia } \\
\text { hiantina }\end{array}$} & MNI - sample & 29 & 174 & 157 & 85 & 101 & 125 & 14 \\
\hline & MNI - \% & 43.2 & 60.8 & 51.2 & 47.8 & 48.7 & 59.6 & 54.0 \\
\hline & Weight - Sample & 60 & 380 & 310 & 218 & 240 & 365 & 33 \\
\hline & Weight - \% & 14.7 & 26.0 & 18.6 & 21.4 & 21.5 & 34.0 & 23.5 \\
\hline \multirow{4}{*}{$\begin{array}{l}\text { All other } \\
\text { species }\end{array}$} & MNI - Sample & 10 & 15 & 24 & 8 & 14 & 27 & 3 \\
\hline & MNI - \% & 14.1 & 5.2 & 7.8 & 4.5 & 6.8 & 12.6 & 11.6 \\
\hline & Weight - Sample & 76 & 95 & 89 & 48 & 62 & 158 & 33 \\
\hline & Weight - \% & 18.6 & 6.5 & 5.3 & 4.7 & 5.5 & 14.7 & 23.5 \\
\hline
\end{tabular}

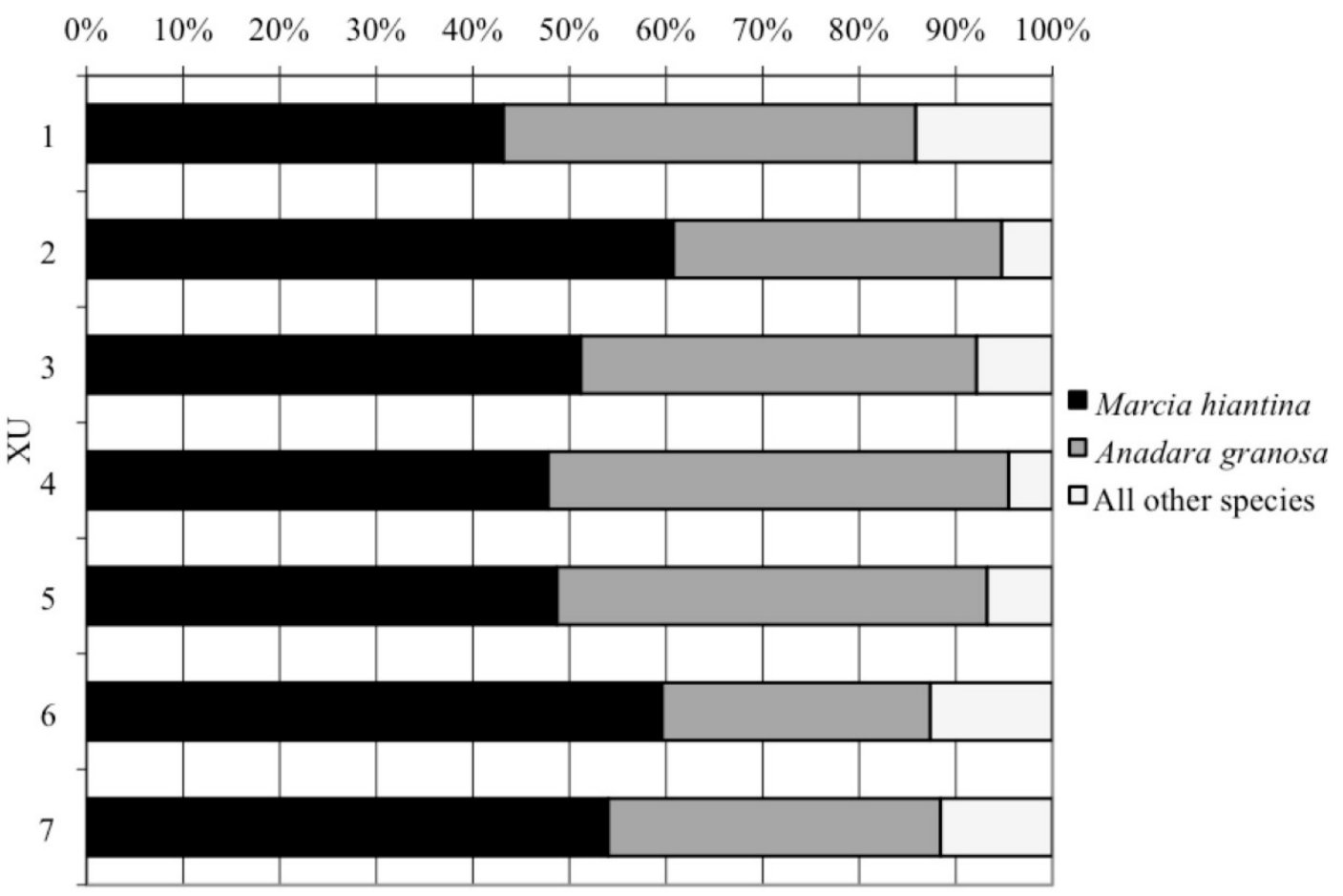

Figure 14. Shellfish MNI data, SM:88. 
Table 13. Non-molluscan faunal materials, SM:88.

\begin{tabular}{|l|c|c|c|c|c|c|c|c|}
\hline & XU1 & XU2 & XU3 & XU4 & XU5 & XU6 & XU7 & Total \\
\hline Otoliths (\#) & - & - & - & 1 & - & - & - & 1 \\
\hline Crab Fragments (g) & - & 5 & 5 & 5 & 5 & 1 & - & 21 \\
\hline Other Bone (g) & - & 5 & 2 & 3 & 4 & - & - & 14 \\
\hline
\end{tabular}

Table 14. Stone artefacts, SM:88.

\begin{tabular}{|c|l|l|r|r|r|r|}
\hline XU & Raw Material & \multicolumn{1}{|c|}{ Type } & \multicolumn{1}{c|}{$\begin{array}{c}\text { Cortex } \\
(\mathbf{\%})\end{array}$} & \multicolumn{1}{c|}{$\begin{array}{c}\text { Length } \\
\text { (mm) }\end{array}$} & \multicolumn{1}{|c|}{$\begin{array}{c}\text { Width } \\
(\mathbf{m m})\end{array}$} & \multicolumn{1}{|c|}{$\begin{array}{c}\text { Thickness } \\
(\mathbf{m m})\end{array}$} \\
\hline 1 & Silcrete & Broken flake & $51-99$ & 36 & 32 & 13 \\
\hline 3 & Milky Quartz & Broken flake & 0 & 13 & 13 & 8 \\
\hline 4 & Quartz & Angular fragment & 0 & 12 & 8 & 5 \\
\hline
\end{tabular}

Table 15. Summary of results of $2 \mathrm{~mm}$ residue analysis, Prunung.

\begin{tabular}{|c|c|c|c|c|c|c|c|c|c|c|c|c|c|c|c|c|}
\hline \multirow[t]{2}{*}{$\begin{array}{l}\text { Site } \\
/ \mathbf{X U}\end{array}$} & \multirow{2}{*}{$\begin{array}{c}\begin{array}{c}2 \mathrm{~mm} \\
\text { Residue }\end{array} \\
\mathrm{g} \\
\end{array}$} & \multirow{2}{*}{$\begin{array}{c}\text { Charcoal/ } \\
\text { Vegetation } \\
\mathbf{g} \\
\end{array}$} & \multicolumn{2}{|c|}{ Bone } & \multicolumn{2}{|c|}{$\begin{array}{c}\text { Stone } \\
\text { Artefacts }\end{array}$} & \multicolumn{2}{|c|}{ Crab } & \multicolumn{2}{|c|}{ Ceriths } & \multicolumn{2}{|c|}{ Land Snail } & \multicolumn{2}{|c|}{$\begin{array}{c}M . \\
\text { hiantina }\end{array}$} & \multicolumn{2}{|c|}{ Trochus } \\
\hline & & & $\#$ & g & \# & g & \# & g & MNI & g & MNI & g & MNI & $\mathrm{g}$ & MNI & g \\
\hline $\begin{array}{l}\text { SM: } 88 \\
\text { XU2 }\end{array}$ & 2547 & 4 & 12 & 0.45 & 2 & 0.02 & 9 & 0.03 & 8 & $<1$ & 35 & 0.6 & 30 & 6 & 1 & $<1$ \\
\hline $\begin{array}{l}\text { SM:91 } \\
\text { XU2 }\end{array}$ & 2662 & 18 & 82 & 3.2 & 4 & 0.7 & - & - & 375 & 23 & 7 & $<0.5$ & 16 & 2.8 & - & - \\
\hline $\begin{array}{l}\text { SM:93 } \\
\text { XU6 }\end{array}$ & $\begin{array}{r}3752 \\
(50 \% \text { or } \\
1904 \mathrm{~g} \\
\text { sorted) }\end{array}$ & 94 & 10 & 0.7 & - & - & 1 & $<0.5$ & 37 & 2.8 & 10 & $<1$ & 27 & 11 & 1 & $<1$ \\
\hline
\end{tabular}


molluscan faunal remains in the $6 \mathrm{~mm}$ residues. A single XU from sites SM:88, SM:91 and SM:93 were investigated. SM:88 yielded the greatest proportions of non-molluscan fauna when $6 \mathrm{~mm}$ residues were investigated (Table 15), however, results of $2 \mathrm{~mm}$ analysis from XU2 did not generate any significant new insights. Less than $0.8 \mathrm{~g}$ of highly fragmented bone and crab shell were found along with two very small angular quartz flakes and a small number of diagnostic $M$. hiantina $(\mathrm{MNI}=30)$ which had a weight of only $6 \mathrm{~g}$ in total. Thirty-five complete land snails, eight small Cerithium spp. and a single small $(<5 \mathrm{~mm})$ probable Trochus spp. shell were also recovered.

Reasonable numbers of bone fragments were recovered from SM:91 ( $\mathrm{n}=82$ fragments), however, these were very small and weighed a total of just $3.2 \mathrm{~g}$. A large number of Cerithium spp. were also recovered with 375 diagnostic specimens identified in the deposit. Four pieces of quartz debitage and a small number of $M$. hiantina (MNI of 16) and unidentified species of land snail $(\mathrm{MNI}=7)$ were also recovered. The third sample investigated was XU6 of SM:93 which yielded less than $0.7 \mathrm{~g}$ of fragmented, nondiagnostic bone.

Results of analysis of a subsample of $2 \mathrm{~mm}$ residues are consistent with the results of more in-depth analysis of $6 \mathrm{~mm}$ residues. The key point of difference is that a large number of Cerithium spp. were recovered in SM:91, with 31 individuals recovered in $6 \mathrm{~mm}$ residues and 375 in $2 \mathrm{~mm}$ residues. This clearly has implications for our understanding of shellfish composition of this XU and the entire site. Implications of this are explored in more detail below.

\section{Discussion}

Excavation, analysis and radiocarbon dating of six shell mound sites at Prunung, together with previous work by others (Bailey et al. 1994), provide important insights into the patterns of shell mound development and the focus of Aboriginal food production strategies. In this concluding discussion key trends in these data are highlighted with particular attention given to shell mound composition and the chronological relationships between sites.

\section{Spatial and Temporal Patterns}

The results presented above provide important new data on spatial and temporal patterns in shell mound deposition at Prunung, though these data are not without limitations. Of most concern is that several of the sites at Prunung (namely SM:96 and SM:93) are large, complex features whose depositional histories are unlikely to be fully understood through the limited dating programme conducted to date. Chronological data for SM:96 illustrates this problem well, because a number of inconsistencies appear in the determinations. While recent human disturbance and natural processes may account for anomalies on this exposed and heavily impacted site, it still highlights the likely complex depositional history associated with the formation of larger mounds: simply put, linear (or upward) accumulation should not be assumed but instead needs to be demonstrated (see also Stein and Deo 2003). The radiocarbon determinations obtained for SM:93 and SM:92 do not indicate any obvious anomalies in accumulation, although given their large basal dimensions (50m x 30m and $30 \mathrm{~m} \times 10 \mathrm{~m}$, respectively) it is unlikely these dates encapsulate the potential complexity of discard activities in these areas. A more thorough assessment of accumulation rates across the mound is required and this would necessarily involve a more extensive dating programme; however, this would necessitate more invasive work which was undesirable from the point of view of Thanakwith custodians. The smaller sites of SM:91, SM:90, SM:88 and SM:86 pose fewer difficulties in terms of interpreting radiocarbon dates as deposition has been more constrained and focussed upon a smaller area. While these are more likely to reflect vertical accumulation, it is nevertheless the case that their broad basal dimensions do not rule out the possibility of spatial and temporal discontinuities in mound accumulation.

Despite these issues it is possible to develop a broad, preliminary framework of spatial and temporal patterns of shell mound formation at Prunung. Available calibrated age spans for basal radiocarbon determinations (Figure 15) suggest initial deposition on the northeastern-most sites between $\sim 500$ and $\sim 850$ cal BP, evidenced by the basal age estimates for SM:93, SM:90 and SM:92. Following this, there appears to have been concentrated discard activity across a 500m area for at least the past $\sim 550-600$ calendar years, with SM:96 possibly developing more recently than those to the northwest. Furthermore, it seems likely that development of this group of sites did not occur in succession: that is, discard in a new area does not seem to have started following abandonment of an earlier site. Instead, occupation appears to be archaeologically contemporaneous. After $\sim 550-380$ cal BP, two new discrete deposits are established: SM:86 and SM:88, both of which are located in unique contexts away from the primary complex of sites. SM:86 is located adjacent to a stone pavement which provides a natural access point through dense mangrove forest to open mudflats. SM:88 is located $500 \mathrm{~m}$ inland from the nearest shoreline but in an area which is immediately adjacent to messmate woodlands. Current determinations on the underlying substrates, obtained by Stone (1995), suggest that the mound was not linked to use of the area when the shoreline was further inland, so it is clearly the case that people elected to transport shell a short distance inland, despite the occurrence of contemporaneous mounds adjacent to the shoreline.

Importantly, radiocarbon data for Prunung provides clear evidence of continued use of the area up until the most recent part of the radiocarbon calibration curve (i.e. they are modern). SM:91 was constructed on the northern margins of SM:92 and a single determination yielded an essentially modern calibrated age estimate. This result, together with the discovery of a small glass flake in the near basal deposits of this site, supports the proposition that deposition continued in this area for at least a short time after the arrival of Europeans in the region after the 1880 s.

\section{Site Stratigraphy and Composition}

Stone (1995:94) argued that the T. granosa-dominated mounds that occur parallel to the shoreline at Prunung are natural phenomena and that there was no evidence they were collected as food by Aboriginal people. It is argued here that his interpretation of shell mound deposits at Prunung is based on spurious data. He used column samples obtained across the beach ridge sequence in three transects (Stone 1995:Figure 6a). Only one of these 


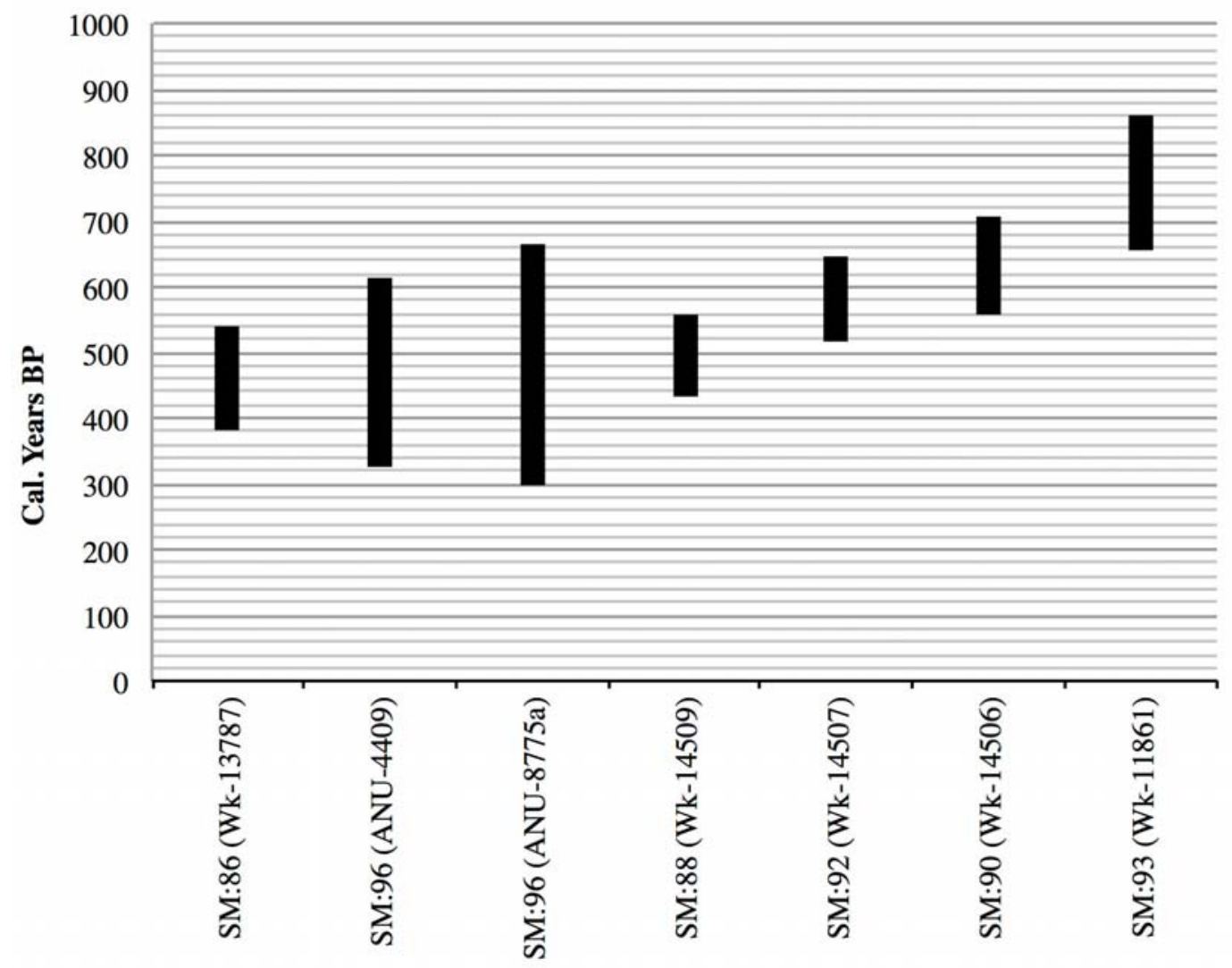

Figure 15. Calibrated age spans for basal radiocarbon determinations, Prunung.

transects (A-B) included a distinct shell mound deposit, while the remaining two (C-D and E-F) were a further $300 \mathrm{~m}$ and $800 \mathrm{~m}$ to the northeast (towards Prunung Creek), where no shell deposits interpreted as anthropogenic have been recorded. According to Stone's (1995:Figure 6) results, only one column was obtained from a potential anthropogenic deposit. In this case, his column sample appears to have been taken from this feature's landward lower flank, where intermixing with natural substrates is likely to be greatest, yet no comparative data on the composition of this column sample in relation to surrounding substrates are provided. Importantly, such detailed comparative work has been carried out by others, and clearly illustrates the distinctive nature of these deposits in relation to the substrate; this has supported conclusions that these sites are of anthropogenic origin (Bailey 1993; Bailey et al. 1994).

New data from a wider range of sites presented here also refute Stone's claims about the natural origin of shell mound sites at Prunung. A clear attribute of the SM:93, SM:91, SM:86 and SM:88 sites is their compositional and stratigraphic distinctiveness compared with their underlying substrates. In all cases shell mound substrates were sand-dominated with negligible amounts of whole large shell and large proportions of bauxite pisoliths. Shell hash, small whole shells and sparse $T$. granosa were occasionally noted, particularly in the substrates on which SM:93 and SM:91 were found. However, shell mound deposits were composed of a restricted range of species of known economic importance, alongside small proportions of species of no known economic importance, such as Cerithium spp., discussed below. These deposits contained overall low proportions of bauxite pisoliths and lacked the sand-dominated matrix evident in the site substrates. Furthermore, there are strong similarities in site stratigraphy with those sites excavated at Bweening, where any influence from naturally-deposited shellfish has been previously ruled out (Morrison 2013b).

The site SM:88 also provides perhaps the strongest support for the claim that shell mound deposits at Prunung are of anthropogenic origin. This site occurs in an area that is above or beyond the influence of any substantial marine deposition processes within the past few thousand years as it is located over $400 \mathrm{~m}$ from the modern shoreline inland of a substantial seasonal swamp. The site occurs on an inland sand ridge that is likely to be at least 2401-2833 cal BP (ANU-8036) based on Stone's (1995) own chronology for beach ridge formation. If this site had a natural origin then it would need to be composed of naturally occurring shells from the surrounding substrate, and of a similar age to its substrates. Furthermore, the possibility that SM:88 is the result of a scrub fowl scraping non-mounded anthropogenic shell deposits into a mound is also not considered to be applicable. At best, only very sparse shell is found within the surrounding substrates and there are no remnants of non-mounded anthropogenic shell deposits in the area that scrub hens could have scraped into a mound.

There is little question that Aboriginal people were responsible for constructing shell mound sites at Prunung. This is supported by their close similarities with anthropogenic mounds at Bweening, the contrast in their composition compared with underlying substrates and their overall stratigraphy and appearance. This does not imply a lack of any influence of natural processes on these sites for it is clear that some have at times been influenced by coastal deposition process. For example, several fine lenses 
or layers of sand occurred in SM:93 (see Figure 7) and both this site and SM:91 had larger proportions of small Cerithium spp. than SM:86 or SM:88, which are less exposed to coastal processes. Furthermore, both sites evidence increasing proportions of these species with depth and this indicates they were deposited when the shell mounds were lower in height when they were possibly more exposed to storm surges.

The occurrence of small proportions of Cerithium spp. in other deposits away from the influence of marine processes, including at the adjacent study area of Bweening (Morrison 2013b), also hints at the addition of what could be best described as 'by catch' to the mounds. Cerithium spp. are relatively small (often $<15 \mathrm{~mm}$ long) and are at times found in very large numbers on intertidal flats, so could be easily intermixed with sediment attached to other shellfish species and incidentally transported to the site. At $\mathrm{SM}: 91$, investigation of $2 \mathrm{~mm}$ residues clearly demonstrated that a reliance on $6 \mathrm{~mm}$ residues alone clearly has a potential to miss large numbers of Cerithium spp. This has implications for future sampling strategies, particularly where mound origins are questionable. The implications of this for quantifying shellfish consumption through time are discussed in more detail below.

Although broadly similar, there are minor stratigraphic variations between the sites excavated and analysed at Prunung. The most variable stratigraphic attribute is the proportion of soil and humic material observed in section: some sites, notably SM:96 and SM:93, evidence clear alternating layers of whole clean shell with layers of more fragmented shell and higher proportions of soil and humic materials. SM:88, however, had high proportions of soil or humic material throughout but lacked the distinct alternating layers. Conversely, SM:86 and SM:91 had no such layers and only evidenced whole, relatively clean shell. It is clear that in the case of Prunung, shell mound size has an obvious relationship to the presence of the distinctive layering, with larger and more complex features more likely to demonstrate this layering, an observation also made at Bweening (Morrison 2013b).

While greater mound size seems to lend itself to the preservation of soil-rich versus soil poor layers, it is also likely related to the presence or absence of vegetation in the surrounding environment and on the mound itself. For example, the two smallest sites (SM:91 and SM:86) which lacked the distinctive alternating soil-rich and soilpoor strata - both occurred in relatively open settings, with little surface vegetation other than grasses and sparse trees in close proximity. They also had little humic material on their surfaces. Conversely, SM:88, SM:96 and SM:93 all occurred within or in close proximity to small thickets of dry notophyll vine forest and subsequently had variable proportions of humic material on their surfaces, though this was not consistent across their surfaces. It was also observed that organic materials tended to collect in depressions and in areas sheltered from wind by trees, grasses and low shrubs. The existence of dark humic strata within mounds might therefore reflect periods where shell accumulation was not occurring, at least on a portion of a former mound surface, enabling enough time for the accumulation of humic materials at the surface and their eventual interpenetration into the underlying shell-rich matrix.
These organic-rich strata are later buried by subsequent shell accumulation, contributing to the distinctive stratigraphic pattern of dense shell matrix with little soil and more frequent whole shell, alternated by strata with greater proportions of soil and more fragmented shell. It follows then that these strata also post-date the deposition of shell matrix that they have interpenetrated, as their formation requires two preconditions: a lack of shell discard and the existence of vegetation in the surrounding environment - or on the mound itself - in order to create the rich humic layers at the mound surface. This may complicate the interpretation of charcoal-derived radiocarbon determinations, since there is a high possibility that charcoal samples recovered from these strata are natural and potentially post-date the accumulation of shell. The location of these organic strata also needs to be taken into account in reconstructing the formation histories of mound sites, together with other possible indicators of former mound surfaces, such a magnetic susceptibility (Rosendahl, Lowe et al. 2014b) or systematic analysis of fragmentation rates (Faulkner 2013; Shiner et al. 2013).

\section{Shellfish Analysis}

Data on the internal variations in shellfish $\mathrm{MNI}$ at each site have been discussed previously and thus here the focus is on MNI data for each site as a whole. As outlined, shellfish estimates at most sites (SM:88, SM:86, SM:91) were calculated from a subsample of $6 \mathrm{~mm}$ sieve residues and this is an important consideration in discussions of relative species abundance. As such, MNI data are presented together with relevant details on sample sizes here (Table 16, Figure 16).

The presence of substantial proportions of Cerithium spp. in deposits of SM:91 are seen here to reflect the influence of storm surges or wave activity on the site. Their presence in larger numbers in $2 \mathrm{~mm}$ residues is important and highlights the well known problem of the underrepresentation of small shellfish when only larger sieve residues are investigated (Claassen 1998). Cerithium spp. were also present in smaller numbers in SM:93, SM:86 and SM:88. Their presence in SM:93, which is located adjacent to the shoreline, may reflect similar process as suggested for SM:91; that is, the likely occurrence of storm surges in the past. However, as Cerithium spp. are considered to be deposited either as by-catch or through natural processes, their under-representation in $6 \mathrm{~mm}$ sieve residues on which shellfish analyses are based is not seen as particularly problematic for investigating production strategies associated with shell mound formation (see also Faulkner 2013).

T. granosa is the most frequently occurring species across all sites ranging between $46 \%$ and $89 \%$ of total site MNI, with the lowest proportions of the species being found in the smallest site, SM:91. M. hiantina is a frequent species in three of four sites at $9-23 \%$ of total MNI. In many sites it represents the dominant shellfish species at different times, and it is almost always present in all XUs of all sites. Both T. granosa and M. hiantina are species that inhabit intertidal mudflats and this is significant given that collectively these species represent $68-97 \%$ of total site MNI. Again, the lowest proportions of both species are found in SM:91 where collectively they represent $68 \%$ of 
Table 16. Relative shellfish MNI, Prunung.

\begin{tabular}{|c|c|c|c|c|c|c|c|c|}
\hline \multirow[t]{2}{*}{ Taxa } & \multicolumn{2}{|c|}{ SM:86 } & \multicolumn{2}{|c|}{ SM:91 } & \multicolumn{2}{|c|}{ SM:88 } & \multicolumn{2}{|c|}{ SM:93 } \\
\hline & MNI & $\%$ & MNI & $\%$ & MNI & $\%$ & MNI & $\%$ \\
\hline T. granosa & 1738 & 88.76 & 263 & 46.39 & 2136 & 73.15 & 33173 & 80.50 \\
\hline M. hiantina & 179 & 9.12 & 125 & 22.08 & 684 & 23.43 & 6801 & 16.50 \\
\hline S. cucullata & 7 & 0.33 & 52 & 9.10 & 36 & 1.23 & 449 & 1.09 \\
\hline P. erosa & - & - & 2 & 0.35 & 1 & 0.03 & 7 & 0.02 \\
\hline V. cochlidium & 9 & 0.46 & - & - & 36 & 1.23 & 135 & 0.33 \\
\hline$N$. lineata & 4 & 0.20 & - & - & 4 & 0.14 & 154 & 0.37 \\
\hline T. telescopium & 1 & 0.05 & - & - & 6 & 0.21 & 33 & 0.08 \\
\hline Barnacle & 10 & 0.51 & - & - & 2 & 0.07 & 203 & 0.49 \\
\hline Cerithiidae & 5 & 0.26 & 125 & 22.08 & 4 & 0.14 & 84 & 0.20 \\
\hline Land Snails & 5 & 0.26 & - & - & 8 & 0.27 & 52 & 0.13 \\
\hline Ellobium sp. & - & - & - & - & - & - & 8 & 0.02 \\
\hline Melo sp. & - & - & - & - & 3 & 0.10 & - & - \\
\hline Other sub-species & - & - & - & - & - & - & 111 & 0.27 \\
\hline Overall MNI ${ }^{2}$ & \multicolumn{2}{|r|}{1958} & \multicolumn{2}{|r|}{566.14} & \multicolumn{2}{|c|}{2919.79} & \multicolumn{2}{|r|}{41209} \\
\hline Overall Sample $\%^{3}$ & & 46.8 & & 26.84 & & 31.91 & & 100 \\
\hline
\end{tabular}

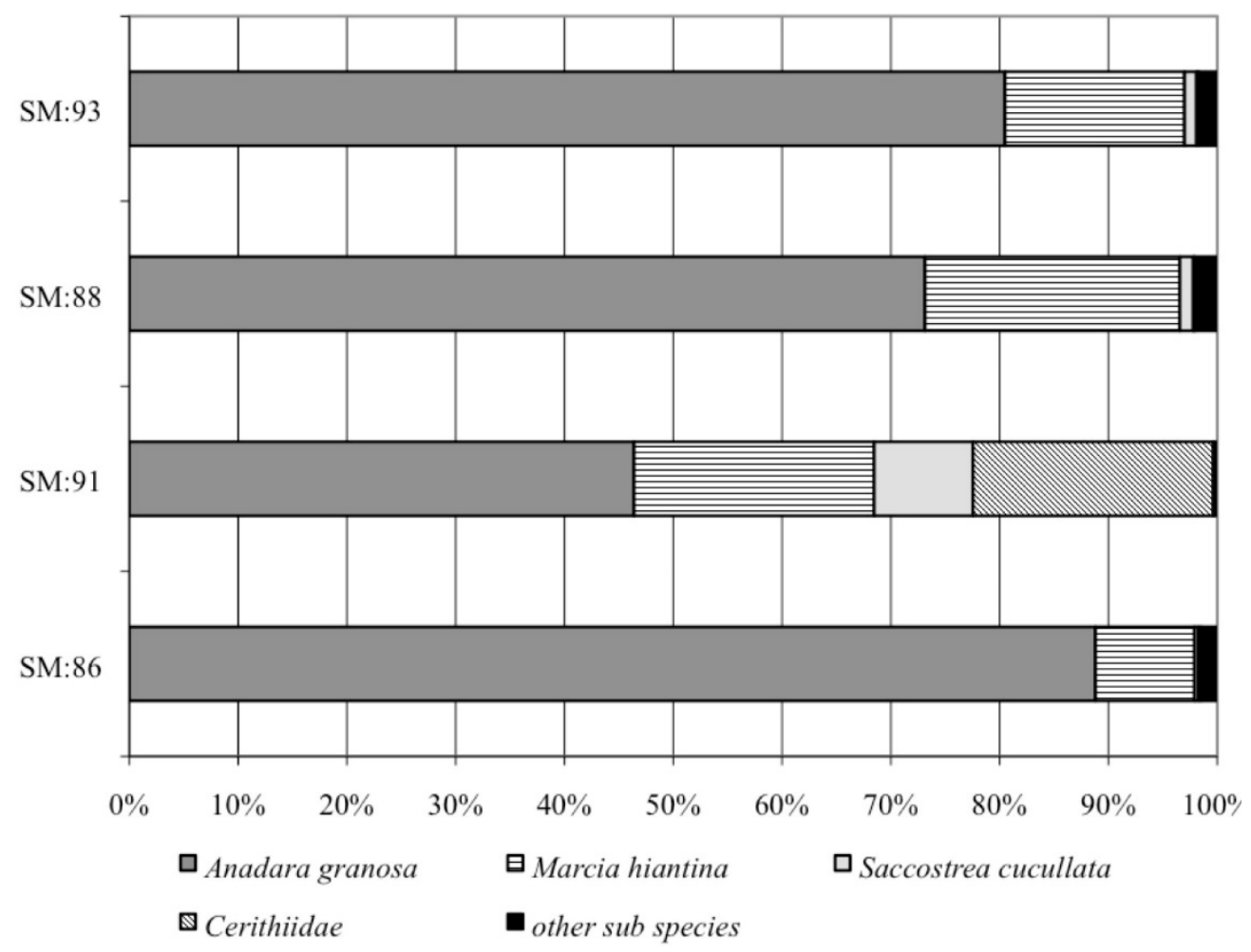

Figure 16. Shellfish MNI summary data, Prunung. 
total site MNI. Here, this lower figure is influenced by the occurrence of much larger proportions of Cerithium spp. than in other sites $(22 \%)$ and as outlined these are thought to be derived from both intermixing with mound substrates and the influence of storm surges depositing material from off site. If Cerithium spp. are omitted as a non-economic species - which seems likely given their very small size (cf. Rowland 1994) - then M. hiantina and T. granosa together represent $90-98 \%$ of total MNI for all excavated sites at Prunung.

Conversely, shellfish species common to mangrove forests and rocky shorelines such as $P$. erosa, $V$. cochlidium, T. telescopium, Nerita spp. and S. cucullata are typically represented in very low numbers. The highest proportion of any of these species is a total MNI of $\sim 9 \% S$. cucullata in SM:91. In addition to the presence of Cerithium spp., a limited range of other small and uncommon shellfish species were recovered, with the greatest proportion of these occurring in SM:93. Those most commonly encountered - albeit in very small amounts - included unidentified species of terrestrial snails, small Trochus spp., Ellobium spp. and Balanus spp. A range of plausible explanations can be found for the incorporation of these and other uncommon species in shell mound deposits. Balanus spp., for example, were occasionally observed attached to $T$. granosa shells recovered during excavations and have also been observed on living $T$. granosa and $M$. hiantina shell collected on mudflats. They are also commonly found on mangrove branches with $S$. culcullata, which today at least are a commonly harvested by removing the entire branch. Other less commonly occurring species may have been accidentally collected, introduced by other animals (such as birds) or of course opportunistically targeted by people for unknown purposes - for example, items of adornment or decoration, food or medicine, or as expedient tools.

\section{Artefacts}

Low proportions of artefacts were recovered in shell mound sites at Prunung. None occurred in SM:86, two occurred in SM:91, three in SM:88 and five in SM:93 (Table 17). Artefacts included modified shell, a single glass fragment and a number of small flakes. The greatest number of artefacts was recovered in the site with the largest amount of excavated deposit, SM:93. Stone artefacts were the most common artefact type, though very small in absolute numbers. Raw material was typically quartz or silcrete.

The modified shells are on an unknown species, but are possibly pieces removed from a larger shell such as Melo spp. Both items were broken and had significant amounts of edge-grinding and modification on their distal ends and as such are unlikely to be a quickly manufactured expedient tool. Furthermore, the distal edge has been ground so that it is rounded and smooth, but lacks visible edge damaged linked to cutting, scraping or prising tasks (Figures 9-10). These artefacts are possibly a part of a tool such as a shell knife or spatulate implement, or an item of personal adornment, such as a shell pendant. No equivalents in museum collections have been identified to date.

The recovery of the glass fragment in SM:91 represented an unusual find. While there is a likelihood that the item may have moved downwards through the deposits, its presence in basal layers is not considered to be anomalous given the recent age of the site. The presence of a distinct eraillure scar and lack of cortex/glass surface suggests that this item is a small flake, probably the byproduct of modification or use of a larger piece of glass. In combination with the young age of this site, it clearly supports the assertion that shell mound use continued at least for a short time following European contact in the region.

\section{Non-Molluscan Fauna}

Investigation of $6 \mathrm{~mm}$ sieve residues indicated low proportions of non-molluscan faunal materials in all sites excavated and analysed (Table 18). While SM:93 had the overall largest weight of non-molluscan fauna, the density per kilogram was similar to that of SM:91. Overall, the highest density of these materials was in SM:88 at 21g of bone, otoliths and crab shell per $100 \mathrm{~kg}$ of deposit. The principal reason for this is the presence of $21 \mathrm{~g}$ of crab claw fragments, typically the dense claw tip, and these are heavier than the small fragments of bone that rarely weighed more than $1-2 \mathrm{~g}$ per fragment. There are significant problems with solely using weight as a measure to estimate the relative abundance of bone, as different skeletal elements and different non-molluscan faunal materials will be over- or under-represented. However, this was unavoidable given that essentially no diagnostic elements were identified apart from a single fragment of mandible in SM:93.

Realistically, the overall numbers of non-molluscan materials are very low and make identification of trends and patterns difficult. The clearest trend that can be noted is a coarse differentiation between mounds near the foreshore and the single site recorded further inland, SM:88. This site does evidence higher numbers of nonmolluscan faunal materials than the foreshore sites. Crab claw fragments are probably from a species of mud crab (Scylla spp.), based on visual comparison with modern examples. The bones recovered were small fragments typically less than $10 \mathrm{~mm}$ in length and the broadest level of identification possible is that they were mammal or reptile bones rather than bird bones. There are overall greater proportions of non-molluscan faunal material in SM:88 (21g per $100 \mathrm{~kg})$ compared with other sites $(<5 \mathrm{~g}$ per $100 \mathrm{~kg}$ ) and this is considered to reflect the location of the site adjacent to seasonal swamps and messmate woodland.

Importantly, investigations of selected $2 \mathrm{~mm}$ residues strongly support the argument that shell matrix sites at Prunung evidence little in the way of non-molluscan faunal remains. Those materials that were found were primarily non-diagnostic with no cranial skeletal elements or any complete skeletal elements recovered. This is not to say that diagnostic elements of non-molluscan fauna are not and will never be found in shell mound sites at Prunung. The key point here is that the numbers of these materials are demonstrably low in those XUs where proportions of $6 \mathrm{~mm}$ non-molluscan faunal remains are greatest. This, along with the results from Bweening, suggest that screen size bias is not the reason for a lack of these materials in shell matrix sites, a conclusion also made by Faulkner (2013:179) for mounds at Blue Mud Bay. 
Table 17. Artefact data, Prunung.

\begin{tabular}{|c|l|l|r|r|r|r|}
\hline Site & \multicolumn{1}{|c|}{ Material } & \multicolumn{1}{|c|}{ Type } & $\begin{array}{c}\text { Cortex } \\
(\mathbf{\%})\end{array}$ & $\begin{array}{c}\text { Length } \\
(\mathbf{m m})\end{array}$ & \multicolumn{1}{|c|}{$\begin{array}{c}\text { Width } \\
(\mathbf{m m})\end{array}$} & $\begin{array}{c}\text { Thickness } \\
(\mathbf{m m})\end{array}$ \\
\hline \multirow{3}{*}{ SM:88 } & Silcrete & Broken flake & $51-99$ & 36 & 32 & 13 \\
\cline { 2 - 7 } & Milky Quartz & Broken flake & 0 & 13 & 13 & 8 \\
\cline { 2 - 7 } & Quartz & Angular fragment & 0 & 12 & 8 & 5 \\
\hline \multirow{5}{*}{ SM:93 } & Quartz & Broken flake & 0 & 10.9 & 8.2 & 3.1 \\
\cline { 2 - 7 } & Quartz & Broken flake & 0 & 14.5 & 8.4 & 3.8 \\
\cline { 2 - 7 } & Shell & Modified & NA & 30 & 26 & 2.2 \\
\cline { 2 - 7 } & Shell & Modified & NA & 31 & 25 & 2.5 \\
\cline { 2 - 7 } & Quartz & Broken flake & $1-50$ & 20 & 10 & 5 \\
\hline \multirow{2}{*}{ SM:91 } & Silcrete & Broken flake & $1-50$ & 35 & 19 & 10 \\
\cline { 2 - 7 } & Glass - Green & Fragment & na & 13 & 9 & 2.6 \\
\hline
\end{tabular}

Table 18. Weights and density of non-molluscan faunal materials, Prunung.

\begin{tabular}{|c|c|c|c|c|c|c|}
\hline Site & $\begin{array}{c}\text { Bone } \\
(\mathbf{g})\end{array}$ & $\begin{array}{c}\text { Crab } \\
(\mathbf{g})\end{array}$ & $\begin{array}{c}\text { Otoliths } \\
(\mathbf{g})\end{array}$ & $\begin{array}{c}\text { Deposit } \\
\text { Weight } \mathbf{( k g})\end{array}$ & $\begin{array}{c}\text { Combined } \\
(\mathbf{g} / \mathbf{1 0 0} \mathbf{~ k g})\end{array}$ & $\begin{array}{c}\text { Bone } \\
(\mathbf{g} / \mathbf{1 0 0} \mathbf{~ k g})\end{array}$ \\
\hline SM:93 & 34.8 & 6.03 & 2.00 & 1033.1 & 4.1458 & 3.3685 \\
\hline SM:91 & 3.00 & 2.00 & - & 108.75 & 4.5977 & 2.7586 \\
\hline SM:86 & - & - & - & 122.8 & - & - \\
\hline SM:88 & 14.00 & 21 & 1.00 & 165 & 21.8182 & 8.4848 \\
\hline
\end{tabular}

\section{Conclusions}

Shell mound formation at Prunung was focussed upon the foreshore area and this has been the case since at least $\sim 800$ cal BP, and seems to have continued until the upper limit of effective radiocarbon dating, or within the past 200 years. All of these shell mounds - including the spatial outliers SM:86 and SM:88 - were constructed within the same period of time rather than in succession and this has implications for understanding the production strategies surrounding shell mound formation and use. SM:86 and SM:88 are highly likely to have developed partly due to their unique micro-environmental contexts. The composition of SM:86 suggests it was primarily concerned with exploitation of shellfish species found on intertidal flats and this is supported by its location adjacent to a natural access point to these environments, as well as the lack of non-molluscan faunal materials and stone artefacts.

A similar explanation could also be applied to the complex of sites adjacent to the shoreline near Prunung Point, which are positioned in close proximity to a gentle sloping beach and the deep channel which flows out into Albatross Bay from Prunung Creek. Extensive areas of intertidal flats occur nearby, however, many of these are only accessible with a short water crossing. Here too, the most significant feature of shellfish composition is a strong preference towards species from intertidal flats and negligible use of other resources. Other resources are minimal across all sites: SM:88 had the greatest proportion of non-molluscan fauna present and evidences a subtly different resource base than other mounds located close to the shoreline, however, taphonomic processes affecting the preservation of terrestrial fauna are poorly understood at present. In any case, shellfish are the primary resource used on this site and results presented here are taken to suggest that other resources were used in a supplementary or incidental manner.

These results add weight to previous interpretations that shell mounds were associated with a highly specialised form of production focussing upon specific ecological niches. Previous work suggested that estuarine or marine ecosystems were the focus (Morrison 2013a), however, this interpretation can now be narrowed: taken together, work at both Bweening (Morrison 2013b) and Prunung clearly indicate that the predominant economic emphasis was on marine shellfish species that could be obtained from intertidal mud and sandflats, while those species from other ecosystems (mangroves, rocky shorelines) are more incidental and vary with local environmental context. $T$. granosa was clearly a major focus of these production systems, however, other species such as M. hiantina were also important - at times comprising up to $23 \%$ of overall site composition. This indicates that hypotheses about mound formation need to accommodate the fact that $T$. granosa was clearly not the only species of interest, and this revised model accommodates these local variations in site composition that are being documented as more data come to light. Further field research is required to clarify the extent of these local variations and to address questions as to why other resources such as fish or terrestrial fauna are so poorly represented in shell mound sites. Furthermore, a fundamental question that is yet to be explored is what was the role of shell mound sites in the context of these production strategies? Both questions are being explored through ongoing research in the region. 


\section{Acknowledgements}

I am very grateful to Thanakwith custodians for permission to conduct these investigations, and for their assistance during the fieldwork. In particular, Gracie John, Richard Barkley, Stephen Hall and the late Dr Thancoupie Fletcher AO provided advice on working on Country and supervised my research. I also thank Ross Stanger and Ed Slaughter for their assistance during the fieldtrips, as well as the many students both at James Cook University and Flinders University who kindly volunteered their time in the laboratory. I also thank Chantal Wight (Archaeology, Flinders University) for assistance with artefact photographs (Figures 8, 9 and 12) as well as Matthew McDowell (Palaeontology, Flinders University) for advice on the terrestrial vertebrate fauna. Finally, Pat Faulkner, Sally Brockwell and Sean Ulm provided valuable comments on the original manuscript.

\section{References}

Bailey, G.N. 1977 Shell mounds, shell middens, and raised beaches in the Cape York Peninsula. Mankind 11(2):132-143.

Bailey, G.N. 1993 Geoarchaeological Explorations of the Weipa Shell Mounds. Canberra: Unpublished Report to the Australian Institute of Aboriginal and Torres Strait Islander Studies.

Bailey, G.N. 1994 The Weipa shell mounds: Natural or cultural? In M. Sullivan, S. Brockwell and A. Webb (eds), Archaeology in the North: Proceedings of the 1993 Australian Archaeological Association Conference, pp.107-129. Darwin: North Australia Research Unit, Australian National University.

Bailey, G.N. 1999 Shell mounds and coastal archaeology in northern Queensland. In J. Hall and I.J. McNiven (eds), Australian Coastal Archaeology, pp.105-112. Canberra: Research Papers in Archaeology and Natural History 31. Canberra: Archaeology and Natural History Publications, Research School of Pacific and Asian Studies, Australian National University.

Bailey, G.N., J. Chappell and R. Cribb 1994 The origin of Anadara shell mounds at Weipa, north Queensland, Australia. Archaeology in Oceania 29(2):69-80.

Beaton, J.M. 1984 Shell Mounds and Prograding Plains at Weipa. Unpublished manuscript, Cape York Collection, Hibberd Library, Weipa.

Bourke, P.M. 2005 Archaeology of shell mounds of the Darwin coast: Totems of an ancestral landscape. In P.M. Bourke, S. Brockwell and C. Fredericksen (eds), Darwin Archaeology: Aboriginal, Asian and European Heritage of Australia's Top End, pp.29-48. Darwin: Charles Darwin University Press.

Claassen, C. 1998 Shells. Cambridge: Cambridge University Press.

Clune, G. and R. Harrison 2009 Coastal shell middens of the Abydos coastal plain, Western Australia. Archaeology in Oceania 44(Supplement):70-80.

Cochrane, G.W. 2014 Marcia hiantina shell matrix sites at Norman Creek, western Cape York Peninsula. Australian Archaeology 78):47-52.

Cribb, R.L. 1986 A preliminary report on archaeological findings in Aurukun Shire, western Cape York. Queensland Archaeological Research 3:133-158.

Faulkner, P. 2013 Life on the Margins: An Archaeological Investigation of Late Holocene Economic Variability, Blue Mud Bay, Northern Australia. Terra Australis 38. Canberra: ANU E Press.
Fletcher, T.G. 2007 Thanakupi's Guide to Language and Culture: A Thaynakwith Dictionary. Sydney: Jennifer Isaacs Arts and Publishing Pty Ltd.

Frankland, K. 1990 Booral: A Preliminary Investigation of an Archaeological Site in the Great Sandy Region, Southeast Queensland. Unpublished BA(Hons) thesis, Department of Anthropology and Sociology, University of Queensland, Brisbane.

Hayne, M. 1992 Late Quaternary Coastal Deposition North-West Cape York Peninsula. Unpublished Honours thesis, Department of Geography, Faculty of Science, Australian National University, Canberra.

Hiscock, P. and F. Mowat 1993 Midden variability in the coastal portion of the Kakadu region. Australian Archaeology 37:1824.

Hogg, A.G., Q. Hua, P.G. Blackwell, M. Niu, C.E. Buck, T.P. Guilderson, T.J. Heaton, J.G. Palmer, P.J. Reimer, R.W. Reimer, C.S.M. Turney and S.R.H. Zimmerman 2013 SHCal13 Southern hemisphere calibration, $0-50,000$ years cal BP. Radiocarbon 55(4):1889-1903.

Morrison, M.J. 2003 Old boundaries and new horizons: The Weipa shell mounds reconsidered. Archaeology in Oceania 38(1):1-8.

Morrison, M.J. 2010 The Shell Mounds of Albatross Bay: An Archaeological Investigation of Late Holocene Production Strategies near Weipa, North Eastern Australia. Unpublished $\mathrm{PhD}$ thesis, Department of Archaeology, Flinders University, Adelaide.

Morrison, M. 2013a Niche production strategies and shell matrix site variability at Albatross Bay, Cape York Peninsula. Archaeology in Oceania 48(2):78-91.

Morrison, M.J. 2013b From scatter to mound: A new developmental model for shell mound sites at Weipa. Queensland Archaeological Research 16:165-184.

Morrison, M.J. 2014 Chronological trends in late Holocene shell mound construction across northern Australia: Insights from Albatross Bay, Cape York Peninsula. Australian Archaeology 79:1-14.

Petchey, F., S. Ulm, B. David, I.J. McNiven, B. Asmussen, H. Tomkins, N. Dolby, K. Aplin, T. Richards, C. Rowe, M. Leavesley and H. Mandui 2013 High-resolution radiocarbon dating of marine materials in archaeological contexts: Radiocarbon marine reservoir variability between Anadara, Gafrarium, Batissa, Polymesoda spp. and Echinoidea at Caution Bay, southern coastal Papua New Guinea. Archaeological and Anthropological Sciences 5(1):69-80.

Reimer, P.J., E. Bard, A. Bayliss, J.W. Beck, P.G. Blackwell, C. Bronk Ramsey, C.E. Buck, H. Cheng, R.L. Edwards, M. Friedrich, P.M. Grootes, T.P. Guilderson, H. Haflidason, I. Hajdas, C. Hatté, T.J. Heaton, D.L. Hoffmann, A.G. Hogg, K.A. Hughen, K.F. Kaiser, B. Kromer, S.W. Manning, M. Niu, R.W. Reimer, D.A. Richards, E.M. Scott, J.R. Southon, R.A. Staff, C.S.M. Turney and J. van der Plicht 2013 IntCal13 and Marine13 radiocarbon age calibration curves 0-50,000 years cal BP. Radiocarbon 55(4):1869-1887.

Rhodes, E.G., H.A. Polach, B.G. Thom and S.R. Wilson 1980 Age structure of Holocene coastal sediments: Gulf of Carpentaria, Australia. Radiocarbon 22:718-727.

Rosendahl, D., K.M. Lowe, L.A. Wallis and S. Ulm 2014 Integrating geoarchaeology and magnetic susceptibility at three shell mounds: A pilot study from Mornington Island, Gulf of Carpentaria, Australia. Journal of Archaeological Science 49:21-32. 
Rosendahl, D., S. Ulm, H. Tomkins, L. Wallis and P. Memmott 2014 Late Holocene changes in shellfishing behaviors from the Gulf of Carpentaria, northern Australia. Journal of Island and Coastal Archaeology 9(2):253-267.

Rowland, M.J. 1994 Size isn't everything: Shells in mounds, middens and natural deposits. Australian Archaeology 39:118-124.

Shiner J.S., P.C. Fanning, S.J. Holdaway, F. Petchey, C. Beresford, E. Hoffman and B. Larsen 2013 Shell mounds as the basis for understanding human-environment interactions in far north Queensland, Australia. Queensland Archaeological Research 16:65-92.

Sim, R. and L.A. Wallis 2008 Northern Australian offshore island use during the Holocene: The archaeology of Vanderlin Island, Sir Edward Pellew Group, Gulf of Carpentaria. Australian Archaeology 67:87-94.

Stein, J.K., J. Deo and L. Phillips 2003 Big sites-short time: Accumulation rates in archaeological sites. Journal of Archaeological Science 30:297-316.

Stone, T. 1995 Shell mound formation in coastal northern Australia. Marine Geology 129:77-100.

Stuiver, M., P.J. Reimer and R.W. Reimer 2005 CALIB 5.0. WWW Program and documentation.

Sullivan, M. and S. O'Connor 1993 Middens and cheniers: Implications for Australian research. Antiquity 67:776-788.
Telford, R.J., E. Heegaard and H.J.B. Birks 2004 The intercept is a poor estimate of a calibrated radiocarbon age. The Holocene 14(2):296-298.

Ulm, S. 2002 Marine and estuarine reservoir effects in central Queensland, Australia: Determination of $\Delta \mathrm{R}$ values. Geoarchaeology 17(4):319-348.

Ulm, S. 2006 Coastal Themes: An Archaeology of the Southern Curtis Coast, Queensland. Terra Australis 24. Canberra: ANU E Press.

Ulm S., F. Petchey, G.E. Jacobsen and D. Rosendahl in prep. Prebomb marine radiocarbon reservoir variability in the eastern Gulf of Carpentaria, Queensland, Australia. Queensland Archaeological Research.

Veitch, B. 1999 Shell middens on the Mitchell Plateau: a reflection of a wider phenomenon? In J. Hall and I.J. McNiven (eds), Australian Coastal Archaeology, pp.51-64. Canberra: Research Papers in Archaeology and Natural History 31. Canberra: Archaeology and Natural History Publications, Research School of Pacific and Asian Studies, Australian National University.

Wright, R.V.S. 1971 Prehistory in the Cape York Peninsula. In D.J. Mulvaney and J. Golson (eds), Aboriginal Man and Environment in Australia, pp.133-140. Canberra: Australian National University Press. 